\title{
Measuring and Interpreting Trends in the Division of Labour in the Netherlands
}

\author{
I. Semih Akçomak • Lex Borghans • Bas ter Weel
}

Published online: 2 June 2011

(C) The Author(s) 2011. This article is published with open access at Springerlink.com

\begin{abstract}
This paper introduces indicators about the division of labour to measure and interpret recent trends in the structure of employment in the Netherlands. Changes in the division of labour occur at three different levels: the level of the individual worker, the level of the industry and the spatial level. At each level the organisation of work is determined by an equilibrium of forces that glue tasks together or unbundle them. Communication costs are the main force for clustering or gluing together tasks; comparative advantage stimulates unbundling and specialisation. The estimates suggest that on average the Netherlands has witnessed unbundling in the period 19962005, which implies that advantages of specialisation have increased. These developments explain to a considerable extent changes in the structure of employment.
\end{abstract}

Richard Baldwin, Luis Garicano, George Gelauff, Edward Glaeser, Suzanne Kok, Arjan Lejour, Anna Salomons, the editor and two referees gave very useful feedback on an earlier version of this research. Seminar audiences at the CPB, IZA in Bonn, the NSI seminar at Maastricht University, the NL2040 workshop at the Ministry of Finance in the Netherlands, the T.A.S.K.S. Workshop at IAB in Nuremberg, the University of Groningen and ZEW are acknowledged for helpful suggestions. Akçomak acknowledges support from the Network Social Innovation (NSI) of Maastricht University.

İ. S. Akçomak

Middle East Technical University, Ankara, Turkey

e-mail: akcomak@metu.edu.tr

L. Borghans $\cdot$ B. ter Weel

Maastricht University, Maastricht, The Netherlands

e-mail: lex.borghans@maastrichtuniversity.nl

B. ter Weel (四)

CPB Netherlands Bureau for Economic Policy Analysis, PO Box 80510, 2508 GM,

The Hague, The Netherlands

e-mail: b.ter.weel@cpb.nl 
Especially at the spatial level it explains a substantial part of the increase in offshoring tasks abroad.

Keywords Trade in tasks · Division of labour · Offshoring

\section{Introduction}

The division of labour has changed over the past fifteen years. Revolutionary progress in information and communication technologies (ICT) has enabled a break-up of the production process, which has had implications for the structure of employment (e.g., Bresnahan 1999; Autor et al. 2006; Blinder 2006 and Baldwin 2010). ICT has changed the way individual tasks can be carried out and it has created new possibilities for communication between workers. ICT has also substantially lowered coordination costs (e.g., Varian 2010). Since firms take advantage of these new opportunities by organising the production process differently, this has changed the task composition of occupations across workers (e.g., Borghans and Ter Weel 2006). The same development also created new opportunities to outsource substantial parts of production to other firms. This changes the organisation of work across industries as well (e.g., Bloom et al. 2009). Finally, production increasingly takes place in global supply chains in which the tasks required to manufacture goods and services are performed in several locations all over the world. This changes the composition of employment across countries as well (e.g., Antràs et al. 2006). These rapid and complex to comprehend developments have triggered concerns that in the end more and more tasks currently performed by Dutch workers can and most likely will be carried out abroad. This modern way of organising work demands a framework for analysing what the consequences are for labour-market outcomes.

The aim of this paper is to document trends in the division of labour in the Netherlands in the most recent period and to shed light on what type of tasks are most likely to be affected by these new technological possibilities to organise production differently. We introduce a set of empirical indicators to measure the possibilities and benefits of separating tasks at the worker, industry and spatial level. These indicators are based on a theoretical framework that defines economic activities as a set of tasks. There are forces stimulating bundling of tasks across occupations, industries and space and forces stimulating the separation of tasks across these three dimensions. We relate these indicators to changes in employment across occupations in the Netherlands to investigate to what extent changes in the optimal division of labour can account for trends in the composition of employment trends in the Dutch labour market.

Our approach builds on the notion that occupations are bundles of tasks. The organisation of these tasks is determined by different forces. It depends on the trade-off between coordination and production costs whether tasks are separated into different occupations or not. When coordination becomes easier it might be beneficial to separate tasks into different occupations. When tasks can be separated from occupations, they could also be leaving the firm (be outsourced). Whether or not this happens depends on the make-or-buy trade-off. Carrying out tasks in-house has a coordination advantage, whereas outsourcing tasks could have a cost advantage. Finally, if tasks 
leave the firm they could also leave the country (be offshored). Whether or not this happens depends on proximity vs. cost advantages. In our framework we introduce indicators to measure these forces of bundling and unbundling of tasks. We introduce measures of connectivity and comparative advantage at the level of the worker, industry and across space. Differences in how tasks are connected determine to what extent tasks belong together and differences in task prices in the labour market measure comparative advantage and show to what extent there is a potential for separating tasks from each other.

Measuring what has been going on in terms of the changes in how work is organised is important to understand changes in the composition of employment. There has been a lot of speculation about the effects of offshoring on employment in Western economies and the subject has been on the international policy agenda for a while now. But, so far, there is hardly any framework suitable for examining some of the basic mechanisms and facts. Recent work by Antràs et al. (2006), Grossman and Rossi-Hansberg (2008) and Baldwin and Robert-Nicoud (2010) provides models to think about the labour-market effects of offshoring, but these models are not easily brought to the data. In addition, the literature has been hampered by the difficulty of finding good proxies for the division of labour at different levels of aggregation and offshoring. Indeed, to measure the effect of offshoring on employment we require a model of differences in offshoring costs across tasks. Our framework and empirical work is among the first attempts to do so. ${ }^{1}$

In our empirical work we focus on the Netherlands in the period 1996-2005. This is a period of rapid change in terms of ICT diffusion. The Internet and modern communication technologies have affected coordination costs especially in this period. In addition, the Dutch economy is a small open economy that should go with the worldwide trends of economic and technological developments to remain competitive (e.g., Ter Weel et al. 2010). Finally, there is no previous work on how recent developments in technology and trade have affected employment in the Netherlands. Earlier work by Borghans and Ter Weel (2006) presents estimates of the division of labour in Dutch firms, but does not look at the individual and spatial dimensions. The only recent estimate for the effects of offshoring on Dutch employment is one from Goos et al. (2009). They present evidence of polarisation in the labour market in terms of employment in a number of OECD countries, including the Netherlands. However, their analysis neither addresses the division of labour nor is it able to present a picture at a sufficiently detailed level to understand the underlying mechanisms of changes in the structure of employment. ${ }^{2}$ Although our sample period is relatively short, it covers

\footnotetext{
1 A recent paper by Criscuolo and Garicano (2010) utilises a measure of offshorability by investigating the legal licensing requirements to execute some tasks. Legal requirements are a burden to offshore tasks that would have been offshored otherwise. Their findings suggest that jobs that are "stuck" at home benefit from complementarities with the offshored inputs.

2 CPB (2008) presents a comprehensive analysis of wage inequality in the Netherlands relative to the United States in the period 1979-2005 but does not address the underlying changes in the division of labour. Earlier work on wage inequality in the Netherlands, summarised in Ter Weel (2003), looks at earlier periods and focuses mainly on institutional factors in explaining differences in wages across groups in the Dutch labour market. Gorter et al. (2005) analyse the effects of offshoring for the Dutch economy. They do however not pay attention to employment.
} 
the time in which communication costs have come down rapidly (e.g., Baldwin 2010). This adds confidence to the validity and scope of our analysis.

Our main findings are that the Netherlands has indeed witnessed a period of unbundling of tasks in the past decade. We are able to identify specific tasks and occupations that have been most vulnerable to these developments. Possibilities for unbundling at the individual level are to a large extent comparable to such possibilities at the industry level. These trends are able to explain a large part of the changes in the structure of employment over this period and especially the development at the spatial level can account for the trend in offshoring of activities

An important policy conclusion is that although unbundling at the individual and industrial level is not favourable for the employment probabilities of relatively loweducated workers, the employment risks for this group are not larger than for others. The reason for this is that the link between the tasks performed by relatively low-skilled workers and local demand is stronger than for tasks carried out by higher skilled workers. Thinking in terms of clusters of activities provides an interesting tool for policy makers to reduce the vulnerability to offshoring of regions in the Netherlands.

Our work is related to the research focussing on explaining changes in the structure of employment and wage inequality (see Acemoglu and Autor 2011, for an overview of this literature). Particularly the recent body of work by Autor et al. (2006), Goos and Manning (2007), Goos et al. (2009), Firpo et al. (2009) and Criscuolo and Garicano (2010) shows that certain types of occupations seem to be disappearing in terms of employment shares and/or seem to be paying lower wages over time. Firpo et al. (2009) show that offshoring and technological change accounts for about half of the changes in the US wage distribution between the early 1980s and 2002. Second, from a firm's organisational perspective Osterman (1994), Caroli and Van Reenen (2001) and Bresnahan et al. (2002) suggest both independent and complementary effects of organisational change and computer technology adoption on the demand for labour in Britain, France and the United States. These studies focus on decentralisation of authority within firms. The changes in the assignment of workers to tasks we focus on are related to papers by Autor et al. (2003), Borghans and Ter Weel (2004, 2006), Borghans et al. (2006), Borghans et al. (2008), Garicano and Rossi-Hansberg (2006), Spitz-Oener (2006) and Green (2009). Third, trade economists now recognise that most trade is in intermediate products. Feenstra and Hanson $(1996,1999)$ show that outsourcing has contributed to an increase in the relative demand for skilled workers in the United States. The fragmentation of production into intermediate products suggests that changing the internal composition of sectoral production is a potential channel through which trade affects the demand for labour. However, this literature neglects the division of labour. Trade economists have recently begun to study how technology has facilitated the breaking up of occupations into tasks and how falling costs of offshoring affect factor prices. Most prominently, the theoretical work by Grossman and Rossi-Hansberg (2008) combines the work by labour economists on the importance of tasks and the work by trade economists on the breaking up of the supply chain to study the effects on wages. They point to the role of improvements in communication and transportation technology in explaining the unbundling of the 
production process. ${ }^{3}$ As technologies improve, it becomes more beneficial to fragment the production process to take advantage of cross-country differences in the cost of performing tasks, or producing (intermediate) goods. Empirically, Crino (2010) estimates suggest that service offshoring from the United States has led to increases in high-skilled US service occupations since the late 1990s.

This paper proceeds as follows. The next section presents the theoretical background of the paper. Section 3 explains how we constructed the database for the empirical analysis. In Sect. 4 we present the empirical strategy and compose the several measures used in the empirical analysis. Sections 5 and 6 present the results. In Sect. 7 we discuss the policy implications and main conclusions.

\section{The Division of Labour}

Discussions about the division of labour enter the economics literature via Adam Smith' Wealth of Nations in which he puts forward the example of the pin factory that benefits from specialisation. It became practical in Henry Ford's production model of the T-Ford and was criticised by Charlie Chaplin in the movie Modern Times. Essentially the idea of the division of labour and the gains from specialisation was already present in Plato's piece The Republic in which he argues: "Quantity and quality are more easily produced when a man specialises appropriately on a single job for which he is naturally fitted, and neglects all others."

\subsection{Modern Times}

Originally Adam Smith (1776) related the division of labour to the extent of the market. Now, more than two centuries later, when markets have become very large, we know that many people within one market perform the same tasks without further specialisation (e.g., Baumgardner 1988). Since the time of Smith transport costs have fallen substantially too, leading to the notion of a global village. However, it did not lead to a degree of specialisation far beyond what people have been expecting, because more subtle communication costs have led to new limitations to specialisation.

Since the 1990s, the division of labour has been heavily influenced by the computerisation of work. The adoption and rapid diffusion of the bundle of new information and communication technologies has been the most radical technological change of the last century, and its development will continue for a number of decades to come. The ICT revolution has caused the costs of many kinds of interactions to drop by making a great many processes operate more efficiently, and it has allowed for the opportunity to engage in new interactions that have become cost effective. Bresnahan (1999) shows that the "computer" as a general purpose technology has had by far the greatest impact on the way we work; and will continue to do so in coming decades, because its

\footnotetext{
${ }^{3}$ Ellison et al. (2010) examine decisions of firms to co-locate to explain co-agglomeration patterns in the United States. Proximity of consumers, thick labour markets, face-to-face interactions to exchange ideas and natural advantages all play a role in the firm's decision making. It turns out that input-output linkages are still important in US manufacturing.
} 
diffusion is far from complete. Also, Varian (2010) presents several important ways in which ICT has lowered coordination costs. ${ }^{4}$

For Smith, time reduction in communication costs as a result of the introduction of communication by water-carriage increased the incentives for specialisation. Obviously, production costs have since then decreased so much compared to communication costs that now a decline in much more subtle communication between workers in the same workplace, already makes a difference. For example, a Boeing 787 Dreamliner is presently produced by 43 firms in 135 locations all over the world. From Boeing's headquarters in Chicago $70 \%$ of all tasks are offshored, a way of producing an airplane that was infeasible before the 1990s. This modern way of production demands a framework of analysing tasks.

\subsection{Framework}

The theoretical notions and empirical observations need an analytical framework to be able to structure what is going on. In general, working activities are not carried out in isolation, but the output of some tasks is the input of others, with the end product being consumed by consumers. For physical production this means that products have to be transported from one producer to the other or to the consumer. On the one hand, carrying out related physical activities next to each other saves on transport costs. On the other hand, different locations all over the world could have cost advantages in the production of specific intermediate inputs. Beyond physical distribution, production requires coordination, consultation, and planning. Here too proximity reduces communication costs, although having different workers producing output in specific locations might have cost advantages. The way work is organised, and the resulting division of labour, depends on these economic forces.

The modern economic stance on the division of labour is that computer technology affects the classical trade-off between productivity advantages of specialisation and communication costs, as studied by Baumgardner (1988), Becker and Murphy (1992), Radner (1993) and Bolton and Dewatripoint (1994). Without denying the potential for innovation that can be associated with the computer revolution, when the trade-off between the benefits of specialisation and the costs of communication determines the division of labour, it is hard to imagine that computer technology did not affect the division of labour. Yet, both increased productivity within specific tasks and increased efficiency of communication will affect the benefits of specialisation and communication costs. This process occurs at different levels: the worker, the industry and the region.

Thinking about two tasks that are needed for the production of one type of output, the decision at each level is whether to bundle these tasks (in a person, a company or a region) or to carry out the two tasks separately (by different persons, in different companies and in different regions).

When production of both tasks is combined in one unit, communication costs will be saved. The larger the costs of communication in case two tasks are carried out

\footnotetext{
${ }^{4}$ See Bresnahan and Greenstein (1996) and Ter Weel (2006) for discussions of how computers have changed production.
} 


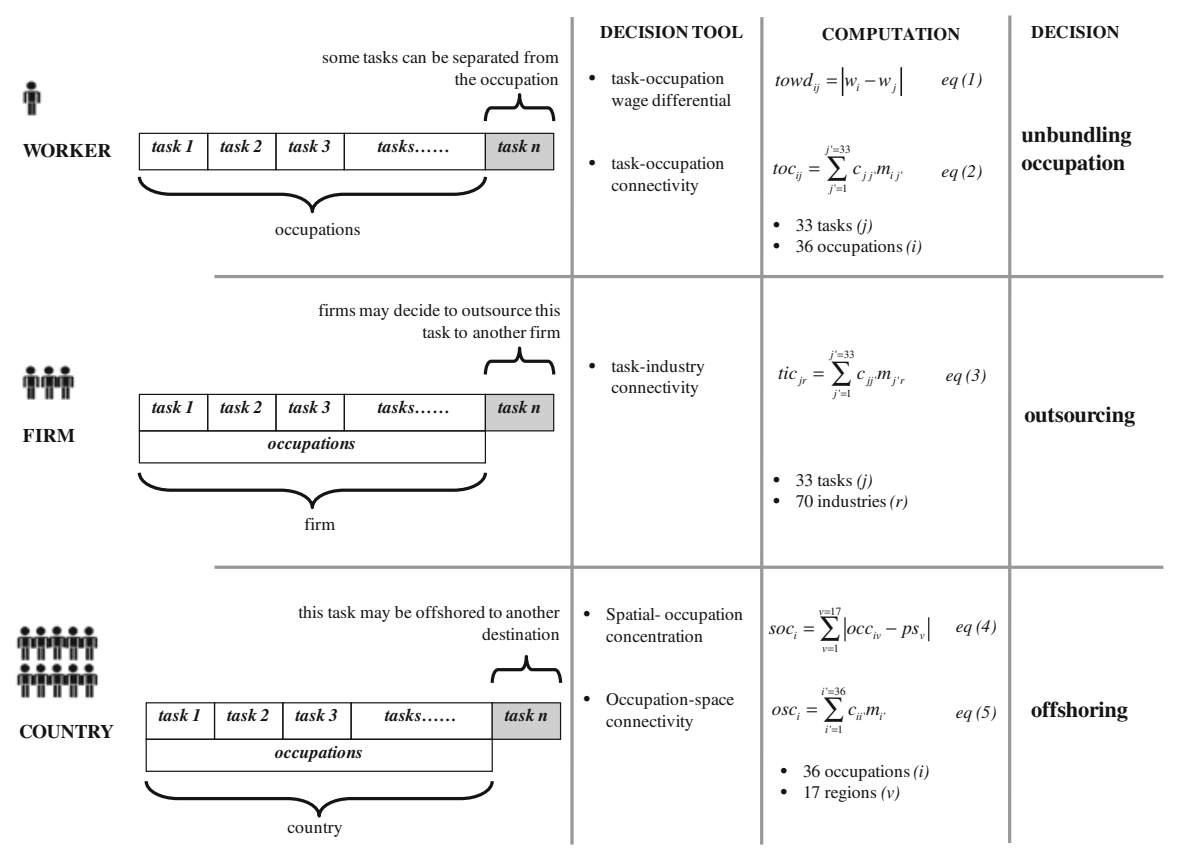

Fig. 1 Framework

separately, the more connected these tasks are. The cost of combining tasks is that no advantage can be taken of comparative advantages of specific units of production. For example, at the individual level, a task that can be carried out equally well by two different types of workers would be allocated most optimally to the worker with the lowest wage. Or, if two workers have the same wage level, one worker could be more productive in one activity while the other specialises in the other activity. The same potential to benefit from comparative advantages applies to the firm and regional level.

These two aspects of the division of labour play a role at three levels of analyses: the worker (individual) level, the firm/industry level, and the spatial (geographical) level. The left-hand side of Fig. 1 provides three pictures of the framework we have in mind. The column in the middle defines the trade-offs between connectivity and price differentials at the three different levels. The right-hand side of Fig. 1 will be discussed in Sect. 4.

At the worker level connectivity means to what extent there are coordination costs involved when two related tasks are carried out by more than one person. If one worker carries out a set of tasks he is automatically aware of the specificities of each task, knows all the details and is aware about the progress of each of the tasks he has to carry out. Assigning these tasks to different workers might require coordination but could increase productivity due to specialisation. Comparative advantage refers to the wage/productivity differential between workers with different skills. Separating tasks makes it possible to benefit from wage or productivity differentials, since the optimal skill level might be different for each task. The classical example is the manager and his secretary. For the firm a secretary is cheaper than a manager and can take over a lot 
of work. But, to make this team work the two need to coordinate activities. The profitability of separating tasks or keeping them together into one occupation depends on the balance of task connectivity and comparative advantage. Technological change might affect the connectivity of tasks, while developments in the wage structure might affect the relevant comparative advantage. Borghans and Ter Weel (2006) show that technologies that improve productivity in a specific task will lead to generalisation since in relative terms coordination costs increase. Technology that facilitates communication will lead to specialisation of work and the separation of tasks into different occupations.

A similar trade-off can be distinguished at the firm level. A firm can buy goods and services in the market or can produce these goods and services in-house. Acquiring these goods and services at the market makes it possible to gain from the productivity and scale advantages of specialised firms. Search and contracting on the other hand lead to coordination costs. It is the balance between make or buy that determines whether tasks are carried our in-house or not. Tasks for which it is not beneficial to separate them at the individual level will also not be separated from the firm. The unbundling at the individual level is therefore a conditio sina qua non for this firm level unbundling.

At the third level, the spatial level, it is distance that constitutes coordination costs. For physical goods it is obvious that distance matters, but also for services it might be important that workers, although possibly working in different firms, can meet each other. There is a strong tendency for economic activities to cluster. Workers in these regions might benefit from contacts with other workers both formally and informally (e.g., Gaspar and Glaeser 1998). ${ }^{5}$ This proximity effect is counterbalanced by the possible cost advantage of offshoring activities to low-wage countries. It depends on the balance between proximity and cost advantages whether or not work will be offshored. At the geographical level also the distance to the customer comes into play. For products with high transportation costs proximity to the client is crucial. Goods that can easily be transported and services that can be carried out at the different location are more easily offshored. In the analysis we are only interested in the costs of distance that have been materialised by separating production across space. Since this analysis is about the division of labour, we neglect the large literature on trade and agglomeration economics that features several types of distance with potentially different effects on location decisions. ${ }^{6}$ In our data this is measured by imports from abroad (see Sect. 4.4).

For each combination of tasks needed for the production of a specific good or service the trade-off between connectivity and comparative advantage determines whether they are bundled (in one person, one firm, or one region) or not. What we actually observe in the data are bundles of tasks. Some of these combinations will be close to the threshold of being changed: A marginal decrease in connectivity or a marginal reduction in comparative advantage could lead to an unbundling of these tasks. With

\footnotetext{
5 Gaspar and Glaeser (1998) report a complementary relationship between ICT and face-to face interactions in the 1970s and 1980s in the US. Venables (2001) shows that this relationship is particularly present in production processes involving skilled activities; low-skilled work is moving to cheaper places (the standardised nature of the work implies that it hardly benefits from face-to-face interactions).

6 See Brakman et al. (2009) for an overview of the trade and agglomeration literature.
} 
a general trend towards unbundling (e.g., Baldwin 2010), it will be particularly these tasks that become unbundled. That is why we investigate in our empirical analyses whether indicators of connectivity and comparative advantage at each level predict tasks becoming less important in an occupation, industry or region. In addition, if some tasks have the potential of being taken out of the bundle of a worker, industry or region, it can be expected that fewer workers are needed to carry out the work. This yields our second type of analysis, which investigates whether indicators of connectivity and comparative advantage predict a decline or rise in the structure of employment. Finally, as unbundled work might be offshored, we investigate whether unbundling at the different levels is related to indicators of offshoring.

Of course, a general trend of unbundling of tasks does not necessarily apply to each combination of tasks or to each occupation. Our approach of documenting this development will show which occupations fit into this pattern, but will also reveal occupations that do not fit into this picture.

\section{Data}

We use several data sources to construct our indicators for connectivity and comparative advantage and the relevant outcome variables. Here we present the most salient details of how we compose the database. Additional and more detailed information can be found in the Data Appendix.

We use three main data sources, which are well-known and often used in Dutch labour market research. First, we use the Dutch Labour Force Survey (Enquête Beroeps Bevolking (EBB)) from 1996 to 2005 to gather information on employment by occupation and other relevant personal characteristics of individual Dutch workers. It also contains spatial information about where workers reside. Each wave of the EBB contains about 85,000 observations. The EBB is a rotating panel and representative for the Dutch labour force. Statistics Netherlands adds weights to the data to assure the data are representative. Since the EBB does not include wage information, we merge the EBB to the administrative wage data of the Sociaal Statistisch Bestand (SSB) and the Dutch Socio-Economic Panel (SEP). The wage data are appended to the EBB based on occupational classifications. For each occupational code we obtain a corresponding wage for each year in between 1996 and 2005.

Second, we need information about work tasks in the Netherlands. Only for Germany (e.g., Spitz-Oener 2006), the United States (e.g., Autor et al. 2003) and Britain (e.g., Green et al. 2007) task data are available. The main advantage of the British data is that it contains uniformly measured information about the importance of job tasks, whereas the German task data only contain information about whether the task or a bundle of tasks is present in an occupation. The US Dictionary of Occupational Titles (DOT) uses different scales for different tasks and requirements. Since these measures are expert ratings, they do not change over time. ${ }^{7}$ For our analysis of connectivity and comparative advantage, having information about the importance of job tasks is crucial to determine whether a task is essential to the performance in an

\footnotetext{
7 The successor of the DOT is $\mathrm{O}^{*}$ Net. This new dictionary contains improved information on job tasks (see e.g., Acemoglu and Autor (2011) for an assessment).
} 
occupation or only of minor importance. The data for Britain are also the most detailed in terms of the number of job tasks and especially designed to address questions about the division of labour. Hence, we use task data from the British Skills Survey (BSS).

The BSS is available for three years (1997, 2001 and 2006) and includes detailed information on the characteristics of individual workers' jobs. ${ }^{8}$ Green (2009) documents the trends in skills requirements using these data; Borghans et al. (2006 and 2008) use all three datasets to explore labour-market outcomes in Britain, Germany and the United States. From the BSS we obtain what tasks are important for different occupations and how important they are (on a scale 1 to 5, with 1 denoting 'not important at all' and 5 denoting 'essential'). We included only the tasks that are considered in all three waves. A typical question on tasks starts with a general explanation "You will be asked about different activities which may or may not be part of your job. At this stage, we are only interested in finding out what types of activities your job involves and how important of these are" followed by the question "In your job how important is ...". The answer categories range from (1) "essential" to (5) "not at all important". We adjusted this scale so that the scale increases with the importance of a task: (5) "task is essentially important" and (1) "task is not important at all". The database consists of tasks, ranging from routine tasks such as the importance of using hands, tools and the importance of physical strength, to more abstract tasks such as the importance of analysing complex problems and planning the activities of others. A list of all 33 work tasks can be found in the Data Appendix.

To append the BSS to the Dutch data, we constructed a crosswalk between the British and Dutch occupational classifications and then aggregated each BSS-wave for 36 large two-digit Dutch occupational classes (see the Data Appendix for more details). We append the BSS to the Dutch data set such that each occupational class in the EBB has corresponding values that measure the importance of tasks. The assumption we make is that Dutch and British two-digit occupations consist of the same set of tasks. For our analysis of 36 large two-digit occupations this seems to be a reasonable assumption because the classes are rather broad and contain relatively many observations. In addition, the employment share in each of the 36 occupations is broadly consistent across the two countries. Only with regard to elementary occupations and managerial jobs we observe some differences across Britain and the Netherlands. If we exclude these occupations from the empirical analysis, our results remain similar to those reported below.

Finally, to be able to calculate offshoring measures we make use of input-output (I-O) tables of Statistics Netherlands (CBS). The Dutch I-O tables yield information regarding the sales and purchases of each industry for the years in between 1996 and 2005. We construct two-digit industry measures of offshoring and add these to the information in the EBB about industry-occupation combinations.

The result of this exercise is a consistent database of personal characteristics and employment shares (EBB), wages of individual occupations (SSB and SEP), the impor-

\footnotetext{
8 The BSS is conducted in 1997, 2001 and 2006. In our data set BSS 1997 refers to the year 1996 and BSS 2006 refers to 2005. We do not expect statistically significant variation in task scores between two consecutive years. To prevent any further confusion we use "task 1996 (2005)" whenever we refer to task score in 1997 (2006) in the BSS data.
} 
tance of job tasks (BSS), and offshoring measures (CBS) from 1996 to 2005. We obtain this information for the 36 largest two-digit occupations and 70 two-digit industries and their interactions.

\section{Measures and Descriptive Statistics}

To document developments in the division of labour we construct measures for connectivity and comparative advantage at the three levels identified in the previous section and displayed in Fig. 1. The right-hand side of Fig. 1 presents the measures and below we show the equations. The Data Appendix at the end of the paper provides a more detailed overview of the measures developed below.

\subsection{Workers}

To measure and analyse the division of labour at the level of the worker we construct two measures: the task-occupation wage differential (to measure the potential for separating tasks by computing the differences in labour-market prices between particular tasks relative to the occupation they are in) and the task-occupation connectivity (to measure the extent to which tasks belong together).

The absolute difference between the occupation wage and the task wage determines the potential productivity advantage from unbundling tasks. The higher the difference between the occupation and task wage, the higher this advantage can be. We calculate the task-occupation wage differential $\left(t o w d_{i j}\right)$ as the absolute difference between the occupation and task wage:

$$
\operatorname{towd}_{i j}=\left|w_{i}-w_{j}\right|
$$

where $w_{i}$ is the occupation wage and $w_{j}$ is the task wage. The index $i$ indexes 36 occupations and $j$ indexes 33 task measures. The occupation wage $w_{i}$ is observed in the data and the task wage $w_{j}$ is constructed by taking the weighted average wage for each task weighting occupations by the importance of that task in an occupation. Higher values of $t o w d_{i j}$ mean a larger discrepancy between the task and the occupation wage, suggesting that based on labour-market prices the specific task belongs less naturally to an occupation relative to a task with an on average low value of $t o w d_{i j} .{ }^{9}$

The second measure is task-occupation connectivity. It measures the presence of a task if another task is part of an occupation. Task-occupation connectivity $\left(t o c_{i j}\right)$ is constructed as follows:

\footnotetext{
9 Ranging from least important to most important, we use [0, 1, 2, 3, 4] as weights to calculate task wages. We experimented with two other weights to see whether this affects our findings. We have applied the rule $[0,1,3,6,10]$ that puts more emphasis on more higher values of importance and $[0,0,0,0,1]$ in which task wages are computed taking into consideration only the most essential task in an occupation. These measures produce task wages that display higher variance. The correlation among the three task-occupation wage differential indicators is at least 0.98 and all correlation coefficients are significant at the $1 \%$ level. The alternative measures yield qualitatively similar regression results.
} 


$$
t_{o c_{i j}}=\sum_{j^{\prime}=1}^{j^{\prime}=33} c_{j j^{\prime}} m_{i j^{\prime}} .
$$

The measure is an occupation-task specific indicator. The index $i$ indexes 36 occupations and $j$ indexes 33 task measures. The variable $c_{j j^{\prime}}$ is an element of a correlation matrix of 33 tasks that shows how tasks are correlated at the worker level. The result is a correlation coefficient for all tasks that shows how connected task 1 is to the other 32 tasks and so on. The correlation matrices are calculated at the individual level in all three BSS rounds (1997, 2001 and 2006). Finally, the correlation coefficients are weighted by $m_{i j^{\prime}}$, which is a measures of the importance of tasks within an occupation. The two indices can be aggregated by occupation and by task.

The two indices differ substantially between the 33 tasks. Figure 2 presents plots of the relationship between the standardised average values of $t o w d_{i j}$ and $t o c_{i j}$ by task. Figure 2a presents the complete picture and Fig. $2 \mathrm{~b}$ presents a more detailed picture of the cloud of points around the median values on both axes. The tasks are abbreviated and in Tables 9, 10 and 11 in the data appendix. A high average level of $t o c_{i j}$ implies that tasks are hard to separate from the occupation. Tasks such as "thinking of solutions", "analysing" and "writing" are relatively well-connected; whereas tasks such as "physical strength" and "selling" are not well connected. Differences between occupation and task wages suggest that it would be beneficial to assign them to separate occupations because when performed by a specialist the tasks could be carried out more efficiently. Together, the two measures determine the profitability to separate tasks from an occupation. High task-occupation connectivity, together with low task-occupation wage differentials mean that it is hard and unnecessary to separate tasks, whereas low task-occupation connectivity together with large task-occupation wage differentials yield scope for separating tasks.

For descriptive purposes we define the difference between the average $t o w d_{i j}$ and $t_{o c_{i j}}$ for each occupation $i$ as the contestability of that occupation. We standardise this variable such that the mean equals zero and the standard deviation equals 1 . The net effect of the two measures is an indicator of the probability that this occupation is offshored. Figure 3 presents the change in employment by occupation against this measure of contestability. ${ }^{10}$ The size of the dots represents the size of the occupations. The pattern in the figure suggests that there is a negative correlation between contestability and changes in occupational employment. This relationship seems to become somewhat blurred towards very high levels of contestability, which can be observed by a tendency towards a positive relationship on the right side of the picture. The most likely explanation for this is one of selection. Although these kinds of occupations are very contestable, the fact that they still exist in the Dutch labour market implies that some of them are still needed in the labour market for reasons not caught by our indicators. The absolute level of employment of these occupations is very low though (small dots), suggesting that these occupations have been under pressure already in

\footnotetext{
10 When we use the change in the hours worked by occupation we obtain similar results. This holds for all analyses throughout the paper.
} 

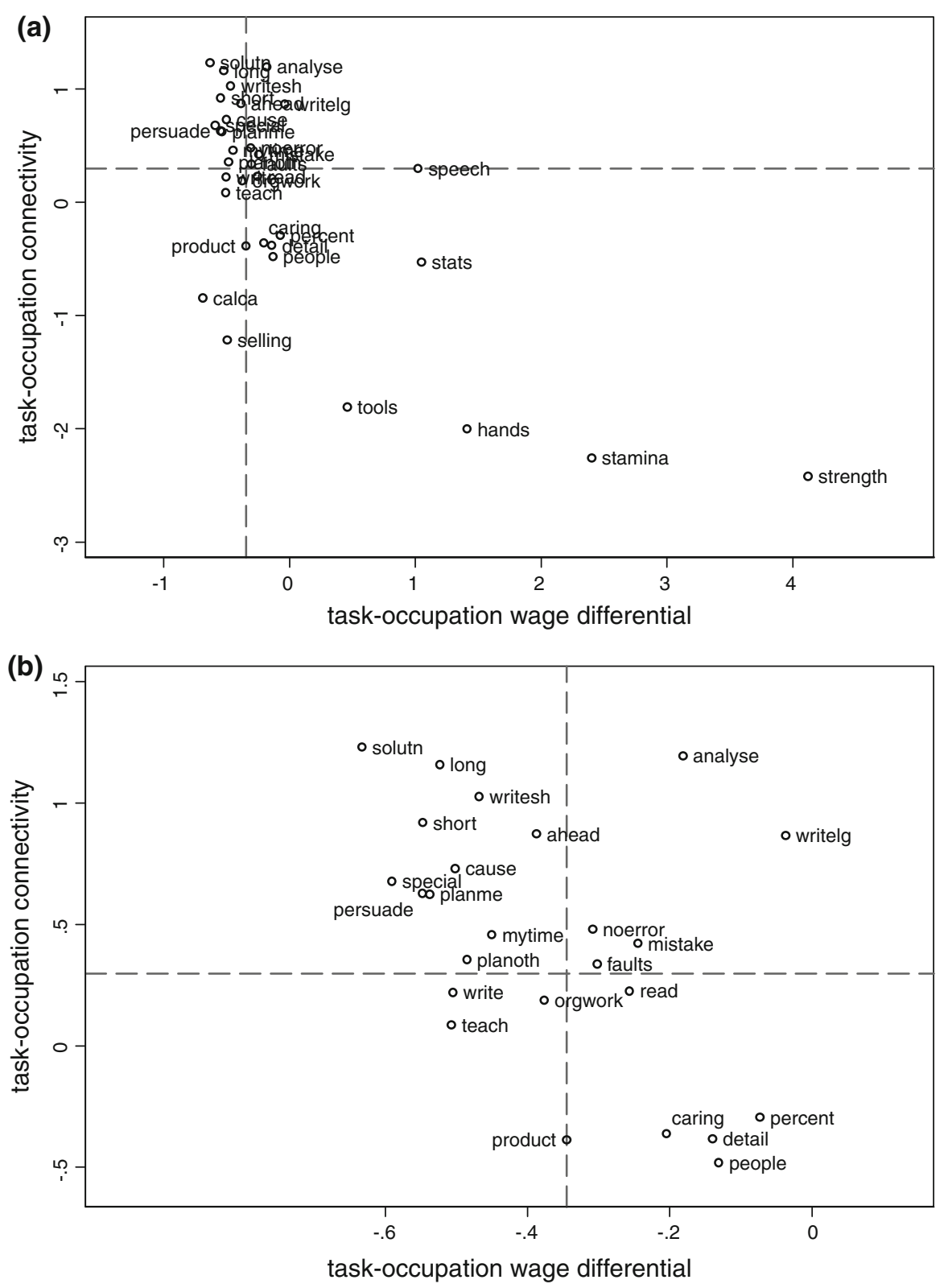

Fig. 2 Task-occupation connectivity and task-occupation wage differentials. Note The unit of observation is tasks. The dotted lines reflect median values. Figure $2 \mathrm{~b}$ is a snapshot of Fig. $2 \mathrm{a}$ of tasks around the median on both axes. A detailed list of tasks are provided in the data appendix. The task-occupation wage differential is defined in Eq. (1) and task-occupation connectivity is defined in Eq. (2). The measures are standardised such that mean is 0 and variance is 1 


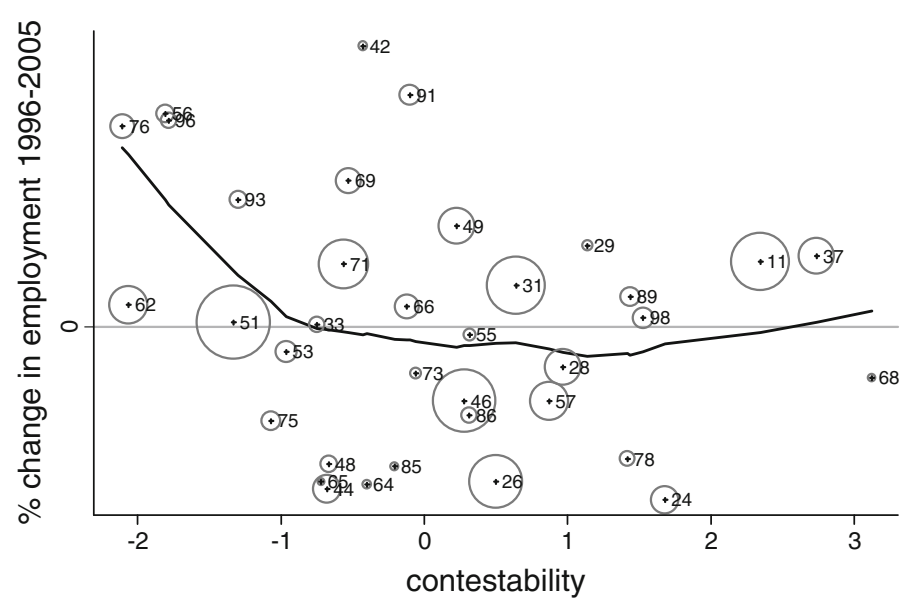

Fig. 3 Contestability of tasks and percentage changes occupational employment, 1996-2005. Note The unit of observation is occupations. The dots refer to occupations and the size of the dots reflects the size of an occupation. The data appendix provides a list of all occupations. Contestability is defined as the difference between the task-occupation wage differential as defined in Eq. (1) and task-occupation connectivity as defined in Eq. (2). The measure of contestability is normalised, see the main text for details

the past. Indeed, closer inspection shows that typical occupations in this area of Fig. 3 are elementary or low-skill occupations and low-end service occupations.

\subsection{Industry}

To measure trends in the division of tasks across industries over the last decade we construct a measure of task-industry connectivity $\left(t i c_{j r}\right)$, where $r$ indexes 70 industries. We assume that there are no task-occupation wage differentials between industries (i.e., $t i w d_{j r}=0$ by definition). In practice there can be differences in the average wages of workers with the same occupation or sets of tasks in different industries. We consider these differences to reflect productivity differentials between sectors due to the selection of workers into industries, which are irrelevant for our analysis of the division of labour.

If it is possible to separate tasks from a worker and assign these tasks to other workers, it is not necessarily the case that these tasks will leave the firm (or the country). Since it is not possible to construct a database that shows tasks (and occupations) by firm for the Netherlands, we use two-digit industry level data. The measure of task-industry connectivity is composed as follows:

$$
t i c_{j r}=\sum_{j^{\prime}=1}^{j^{\prime}=33} c_{j j^{\prime} m_{j^{\prime} r}},
$$

where $c_{j j^{\prime}}$ now measures the task correlations at the industry level. This means that in all three BSS waves the individual level data are aggregated to Dutch industries. The cross-section industry level data show the importance of tasks for each industry 
across all three years. These correlations are then weighted by the importance level of tasks within an industry $\left(m_{j^{\prime} r}\right)$.

The measure of connectivity of tasks at the industry level $\left(t i c_{j r}\right)$ yields a picture of the extent to which tasks are connected to an industry. Similar to tasks connected to occupations $\left(t o c_{j r}\right)$, we expect tasks that are relatively well-connected to industries to be less likely to be leaving the industry. Again the indices can be aggregated by task or by industry.

Figure $4 \mathrm{a}$ shows a scatter plot of the average $t i c_{j r}$ and $t o c_{j r}$ by task. Figure $4 \mathrm{~b}$ is a snapshot of values between 0.2 and 0.3 of $t o c_{i j}$ and between 0.2 and 0.45 of $t i c_{j r}$. The points represent the average levels of connectivity across all three waves of the data. The correlation is positive and significant at the one percent level; the coefficient equals 0.912 . We have included a 45-degree line and expect all tasks to be below this line because it seems easier to separate tasks from a worker than from an industry, i.e. reshuffling the tasks across workers is a sine qua non for outsourcing the task elsewhere. The graph indeed suggests that tasks can be assigned to a specific person but that it is harder to set these tasks apart from the industry. The figure also shows heterogeneity across tasks. Tasks closer to the 45-degree line have a more similar probability of being separated, while tasks further away are more easily separated from the worker relative to the firm. For example, tasks such as physical strength have a more or less equal probability of being separated from the worker and the firm, while analysing is more easily split off a worker's occupation relative to the firm.

\subsection{Space}

The final step of the analysis is space. When it is possible to separate tasks from occupations and from industries, it does not necessarily lead to the offshoring of these tasks abroad. In the spatial dimension there could be advantages to bundle activities, since this reduces transport costs and makes communication between people involved in different related processes easier. Therefore, if occupations are well-connected to other occupations across space, there might be less scope for offshoring. In the spatial dimension also the link between production and consumption becomes relevant. If tasks serve local demand, they are scattered around the whole (or a large part) of the Netherlands. To measure the development of the division of labour across space we construct two measures: spatial occupation concentration (to measure the potential for separating occupations from others) and occupation-space connectivity (to measure how well occupations are connected).

We measure spatial occupation concentration and occupation-space connectivity in terms of occupations instead of tasks. The reason is that although task measures are much more detailed and taken from a unique data source, they are still too abstract to distinguish between regional patterns in a relatively small country such as the Netherlands. For example, in the metal industry and the chemical industry, physical strength is an important task for many blue-collar occupations. The metal industry is concentrated around city $X$, while the chemical industry is concentrated mainly around city $Y$. So, in terms of the importance of tasks we do not see much of a difference 

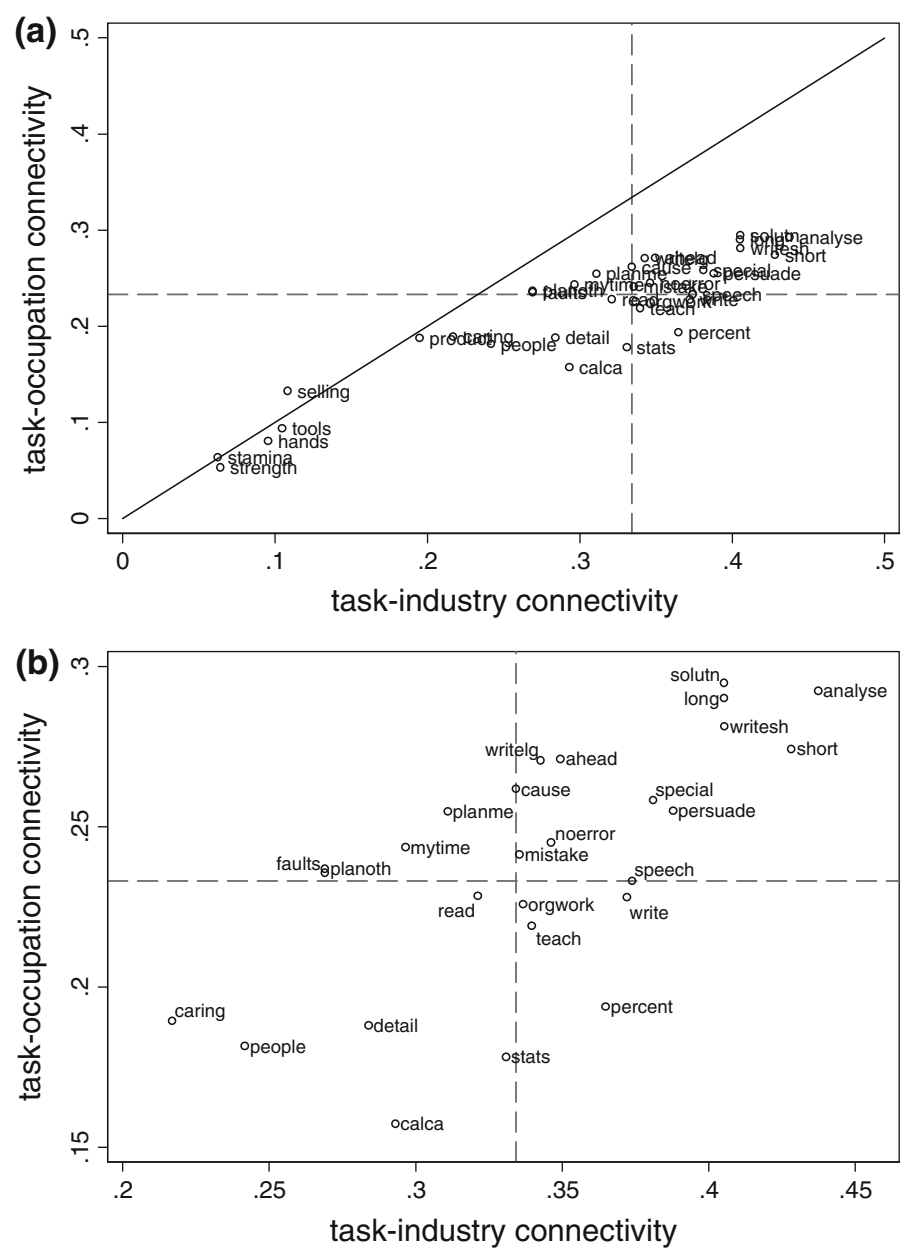

Fig. 4 Correlation between task-occupation connectivity and task-industry connectivity. Note The unit of observation is tasks. The dotted lines reflect median values. The snapshot in Fig. 4b presents the tasks that are hard to discriminate in Fig. 4a. A detailed list of tasks in provided in the Data Appendix. The task-industry connectivity is defined in Eq. (3) and task-occupation connectivity is defined in Eq. (2)

between these cities, while in terms of the probability of offshoring there might be substantial differences. These differences will not be picked up by an analysis of tasks.

The measure of spatial occupation concentration $\left(s o c_{i}\right)$ is an adjusted version of the concentration index proposed by Ellison and Glaeser (1997). The spatial occupation concentration index is calculated as follows:

$$
\operatorname{soc}_{i}=\sum_{v=1}^{v=17}\left|o c c_{i v}-p s_{v}\right| .
$$


In this equation $o c c_{i v}$ is the occupation share of region $v$ and $p s_{v}$ its population share. ${ }^{11}$ We use a regional classification, according to the COROP definition, that divides the Netherlands into 17 different regions. In the equation the first term acts as local employment and the second term as local demand. The difference is traded outside the region. Thus, domestically traded occupations are expected to be internationally tradable as well (e.g., Jensen and Kletzer 2005). A higher score on this measure suggests that occupations are relatively concentrated. More concentration increases the scope to transfer the activity elsewhere.

Occupation-space connectivity $\left(o s c_{i}\right)$ is measured based on the distribution of occupations. We construct an index of occupation connectivity that originates from a matrix of correlations of the share of occupations. Each observation is a region and occupations are variables, so that each cell contains the share of an occupation in a particular region. We obtain a correlation matrix of the share of occupations from this database and apply the same procedure we use to calculate task-occupation connectivity:

$$
o s c_{i}=\sum_{i^{\prime}=1}^{i \prime=36} c_{i i^{\prime}} m_{i^{\prime}}
$$

where $c_{i i^{\prime}}$ is an element of the correlation matrix of occupations that shows the correlation of the share of occupation $i$ with other occupations. The correlation matrix is calculated from the dataset that shows occupation shares for each region. These correlations are weighted by the importance of an occupation, the overall share of occupations in total employment $m_{i^{\prime}}$. A higher score on this measure indicates a higher level of occupation-space connectivity. Higher levels suggest that it is harder to move this occupation elsewhere since it is well-connected to other occupations.

Figure 5 shows the correlation between the measures $s o c_{i}$ and $o s c_{i}$. The dots represent occupations and the size of the dots the size of these occupations in the Netherlands. Again the dotted lines present median values of the two variables. The interpretation of Fig. 5 is similar to the interpretation of Fig. 2. The difference is that we do not measure task-occupation wage differentials but spatial-occupation concentration as a measure of separating tasks. Indeed, the higher the level of $s o c_{i}$, the more contestable an occupation is likely to be. So, again occupations in the south-east quadrant (defined by the medians of both variables) are the ones we expect to be mostly affected by offshoring: these occupations are relatively low-connected and score high on concentration. By contrast, occupations located towards the north-west of Fig. 5 seem to be less contested at this time because they are relatively more spread over the country and relatively well-connected geographically to other occupations. This

\footnotetext{
11 This geographic concentration index is proposed by Spieza (2003). We calculate a second index similar to Ellison and Glaeser (1997) as the square of Eq. (4). However, this measure is sensitive to the level of aggregation. At the regional level the index may under or overestimate the actual spatial occupation concentration due to the fact that differences in occupation and population shares are squared. It is for this reason that we use an adjusted version. The correlation between two indices is 0.81 , significant at the one percent level.
} 


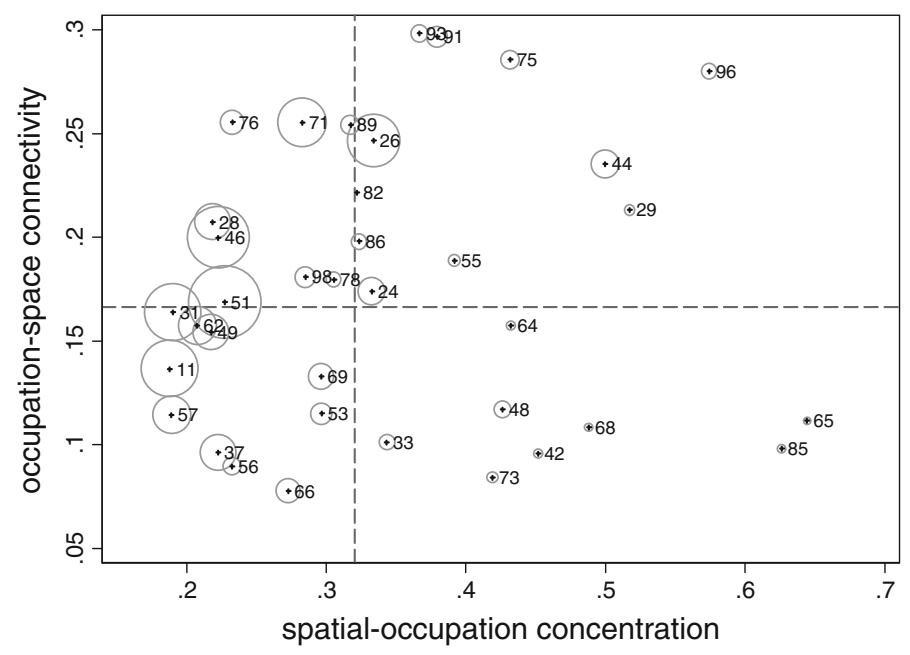

Fig. 5 Spatial occupation concentration and occupation-space connectivity. Note The unit of observation is occupations. The dotted lines reflect median values. A detailed list of occupations in provided in the Data Appendix. The spatial occupation concentration is defined in Eq. (4) and occupation-space connectivity is defined in Eq. (5)

makes it relatively difficult to offshore such occupations. Occupations that are both geographically spread and well-connected are medium-level administrative and service occupations and medium-level government jobs. Examples include workers at stores, municipality agencies and work offices. Among the most contested occupations according to this measure are scientific jobs. They are concentrated and not well-connected to the environment. This is for example consistent with the tendency of firms to relatively easy decide to relocate their research labs in the most recent period.

A simple measure of contestability can be constructed similar to the one we composed for individual workers. We now define the difference between $s o c_{i}$ and $o s c_{i}$ for each occupation $i$ as the contestability of that occupation. We standardise this variable such that the mean equals zero and the standard deviation equals 1 . The net effect of the two measures is an indicator of the probability that this occupation is offshored similar to the one we plotted in Fig. 3 above. Figure 6 presents the change in employment by occupation against this measure of contestability. The size of the dots represents the size of the occupations. The relationship between this measure of contestability and employment changes is (similar to the relationship documented in Fig. 3) negative suggesting that the more contestable occupations have been facing the least employment growth since 1996. In accordance with the notion about the connectivity and lack of spread of research jobs, we observe negative employment growth in the period 1996-2005 for these jobs in the Netherlands (dots 65 and 85).

\subsection{Offshoring}

The final measure we need to construct is a measure of offshoring. The three types of measures developed above are able to explain the connectivity and separability of tasks and occupations but need to be related to a direct measure of offshorability. 
Feenstra and Hanson (1996) measure offshoring based on a proxy of the share of non-energy imported intermediate goods in total non-energy intermediate inputs. The intuition for this way of approaching offshoring is the following: part of the goods that are now offshored have to be brought back to the sending country to be further assembled and/or made ready for final consumption. We calculate an offshoring indicator that shows the amount of imported inputs needed to produce one unit of output taking all embodied imports into account:

$$
\text { offshoring }_{i}=\sum_{r=1}^{r=70} i m p_{r} c_{r i}, i=1, \ldots, 70 \text { and } r=1, \ldots, 70
$$

where $\mathrm{imp}_{r}$ shows non-energy intermediate input purchases of industry $r$ as a share of all input purchases. The second component $c_{j r}$ is an element of the Leontieff inverse matrix $(I-A)^{-1}$ that takes all direct and indirect processes to produce one unit of a product. $A$ is a $70 \times 70$ matrix where the input-output coefficients $a_{i r}$ show intermediate purchases of industry $i$ directly used to produce one unit of industry $r$ output. The result, offshoring, shows embodied imported inputs for each industry. We append this information to the individual level data such that each person has an offshoring indicator depending on the industry of employment. When this is aggregated across occupations we obtain an occupation specific offshoring indicator.

Figure 7 ranks each occupation according to the exposure to offshoring in 1996. The bars are the changes in occupational employment and hours worked in the period 1996-2005. The pattern that emerges is one that suggests that employment and hours worked have diminished in occupations that are more heavily exposed to offshoring. The correlation between the offshoring measure and the two measures of contestability shown in Figs. 3 and 6 is 0.267 and 0.105 , respectively. This pattern reassures us that our measure of offshoring picks up the right phenomenon.

\section{The Importance of Tasks}

To check the empirical relevance of our indicators for the division of labour, we first examine to what extent connectivity and wage differentials at the beginning of the period of analysis (i.e., 1996) are important for explaining changes in the importance of job tasks in the period 1996-2005 at the worker and industry level. To investigate this we first run simple regressions with the difference in task importance as the dependent variable and task-occupation connectivity and task-occupation wage differentials as the main independent ones. We also add the task importance in 1996 as a covariate to address level effects. All regression equations include task and occupation dummies too. All indicators in these regressions have been standardised: a coefficient of one implies that a one standard deviation change in the independent variable changes the dependent variables by one standard deviation (variables that indicate differences are differences of the standardised scores; not the standardised differences). We have chosen this way of reporting because not all variables have a natural metric.

Table 1 shows the results of this exercise at the level of individual workers. Column (1) shows the effects over the entire sample period. The estimates reveal that 


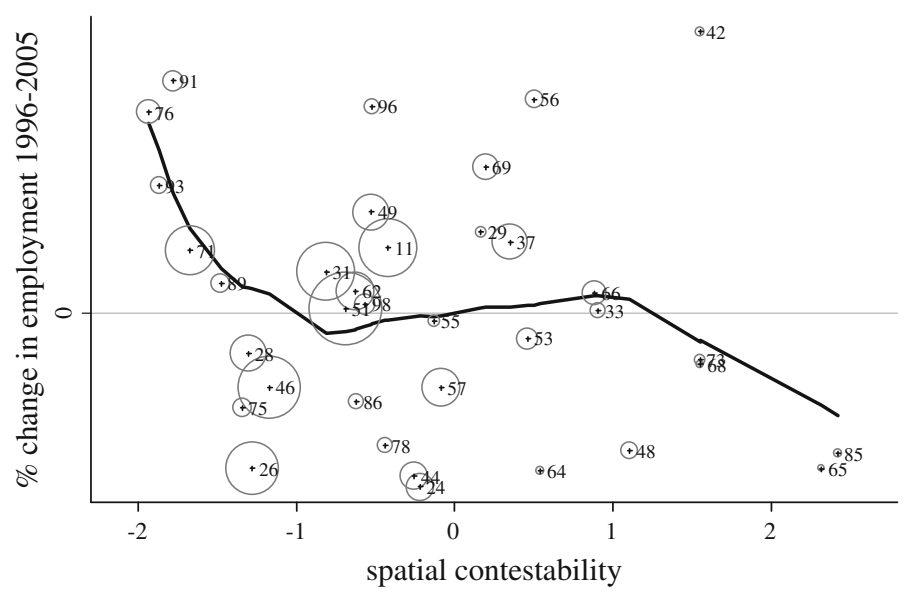

Fig. 6 Spatial contestability and percentage changes in occupational employment, 1996-2005. Note The unit of observation is occupations. The dots refer to occupations and the size of the dots reflects the size of an occupation. The data appendix provides a list of all occupations. Contestability is defined as the difference between the spatial occupation concentration as defined in Eq. (4) and occupation-space connectivity as defined in Eq. (5). The measure of contestability is normalised, see the main text for details

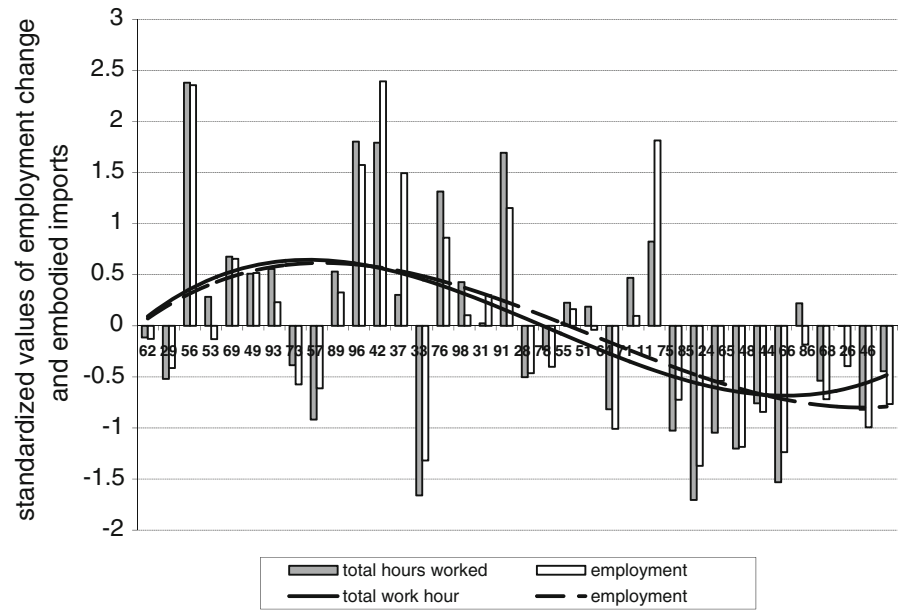

Fig. 7 Occupational employment change 1996-2005 ranked according to embodied imports in 1996. Note The unit of observation is occupations. The horizontal axis ranks occupations according to Eq. (6), such that the highest value of offshoring is at the right side of the graph

tasks that are more connected in 1996 become more important over time. In addition, larger task-occupation wage differentials in 1996 result in a fall in task importance within jobs over time. Borghans and Ter Weel (2006) describe that the simultaneous development of communication and information technologies can lead to more specialisation in certain occupations and tasks and to generalisation in others. The pattern in the data suggests generalisation, although at the margin tasks are unbundled point- 
ing at specialisation. See also Bloom et al. (2009) and Ter Weel et al. (2010) for a discussion of models of specialisation and generalisation.

Column (2) shows the results of the same analysis with only the ten least important tasks within each occupation included; column (4) presents estimates of including the ten most important job tasks; and the estimates in column (3) use the thirteen tasks in the middle. The estimates reveal the same pattern suggesting that we are not picking up the effects of changes in particularly important or unimportant tasks. The effects seem to be present across all tasks. What is worth noticing from columns (2)-(4) in Table 1 is that the task-occupation wage differential is more important for explaining changes in the importance the least important tasks and not of significant importance for explaining changes in the most important job tasks. This suggests that relatively important tasks are core to the job, whereas relatively unimportant tasks are not core to the job. This difference in importance seems to be revealed in differences in their prices.

Finally, we repeat the analysis for two sub-periods, 1996-2001 and 2001-2005. Columns (5) and (6) in Table 1 show the estimates. For the first sub-period the results lead to similar conclusions; for the period 2001-2005 we observe that the task-occupation wage differential does not significantly matter for explaining changes in the importance of job tasks. The estimates suggest that in the second half of the analysed time interval only task-occupation connectivity is important for explaining changes in the importance of job tasks. The task-occupation wage differential seems to have its main effect in the first half of the sample period. ${ }^{12}$

Overall this first set of results points towards a pattern of specialisation of work in the Dutch labour market over the course of the sample period. High-connected tasks seem to gain importance and the coefficients for task-occupation wage differentials suggest that tasks with relatively large task-wage gaps lose importance and could be separated from the occupation. This effect is particularly present in the first half of the sample period and for the least important tasks. Hence, workers seem to give up tasks that do not belong to the core of their job, whereas core tasks (i.e., those with high levels of task-occupation connectivity and low task-occupation wage differentials) gain importance.

A similar analysis is relevant to examine the task indicator at the industry level. In Table 2 we present the results of a regression analysis to investigate whether our measure of task-industry connectivity correlates with changes in the importance of tasks at this level of analysis. We present estimates for the entire period and two sub-periods and control for the initial level of task importance. All regressions include industry and task dummies too.

The estimates presented in column (1) of Table 2 suggest that there is a positive correlation between task-industry connectivity and the change in the importance of tasks, which is consistent with the findings for the occupation-task analysis. In columns (2) and (4) we present estimates for the ten least and the ten most important

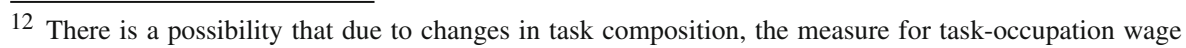
differentials and task-occupation connectivity are affected. To account for this possibility we ran a set of regressions with regressors of task-occupation connectivity in 1996 and task-occupation wage differentials in that year. We obtain similar point estimates to the ones reported in Table 1.
} 


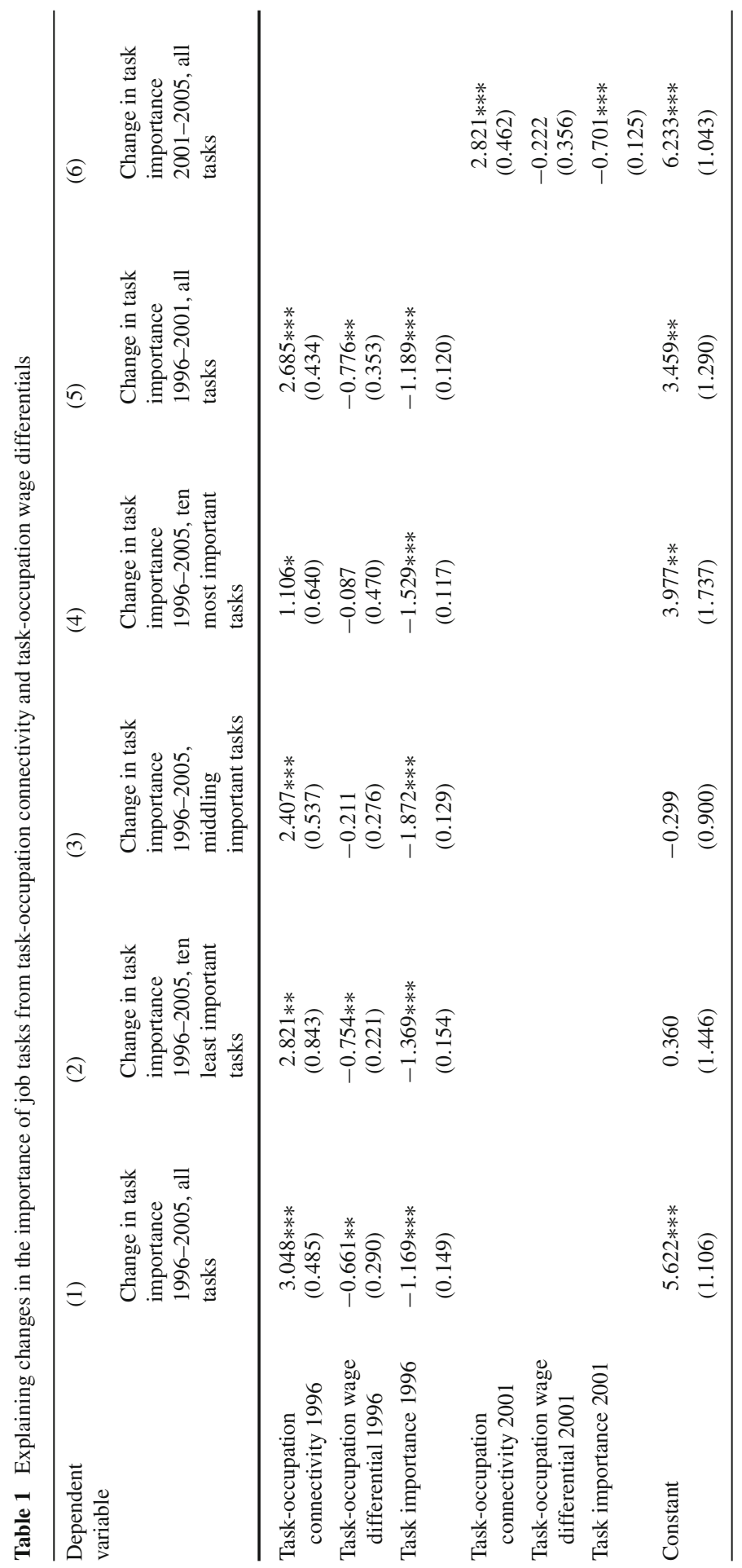




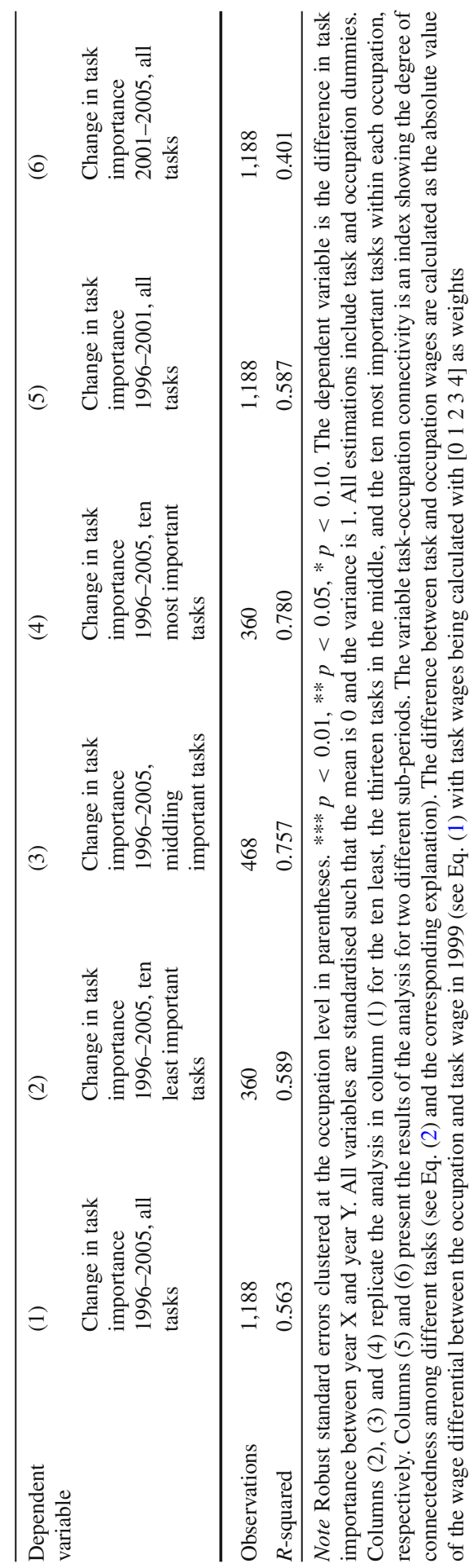




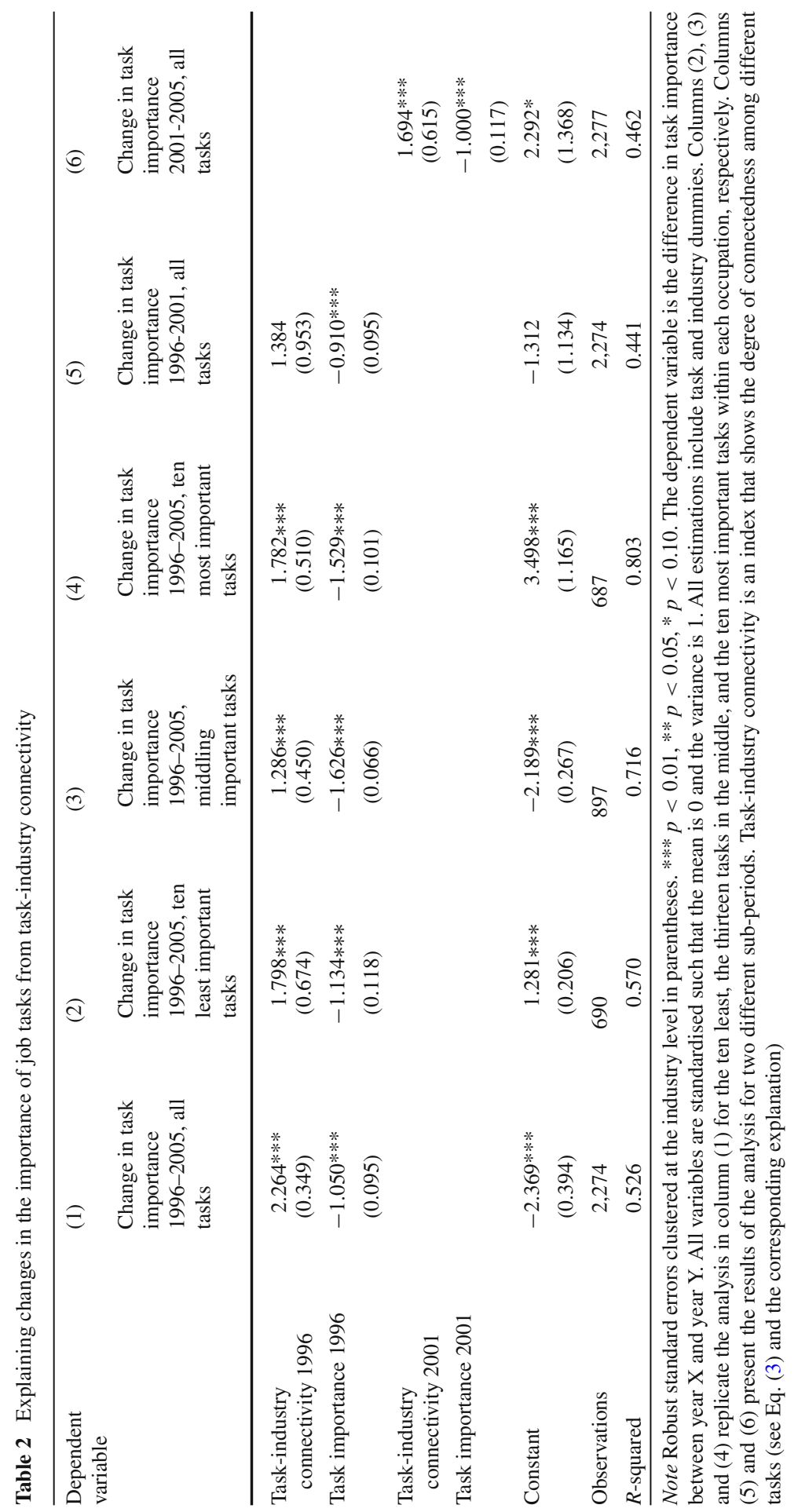


tasks; column (3) presents the estimates from the thirteen tasks in the middle. These estimates are also in line with the ones presented in Table 1. Finally, we split the sample into two sub-periods. The estimate of task-industry connectivity for the first period (1996-2001) presented in column (5) is positive but insignificant, the estimate for the second period (2001-2005) is positive and significant (column (6)). These latter two estimates suggest that the effect of connectivity on the change in the importance of tasks at the industry level is especially present in the most recent period. ${ }^{13}$

Overall, the estimates in Tables 1 and 2 yield a picture consistent with the framework developed in Sect. 2: higher levels of connectivity are positively correlated with the importance of the task to do the job at both levels of analysis and higher levels of task-wage differentials are negatively correlated with core tasks suggesting that there is scope for separating these tasks from the occupation.

\section{Estimation Results}

Based on the set of indicators for the division of labour we are now able to investigate to what extent changes in the composition of occupational employment can be explained by the process of unbundling of tasks. We proceed in Sect. 6.1 with presenting simple regression results to examine employment changes. The next section shows what fraction of the changes in occupational employment we are able to capture with our approach. Finally, we analyse the impact of offshoring on occupational employment in the Netherlands in the period 1996-2005.

\subsection{Changes in Employment}

Table 3 presents the results of a simple regression analysis in which we explain changes in occupational employment over the period 1996-2005 by task-occupation connectivity, task-occupation wage differentials and a number of covariates. The first column presents OLS estimates. The estimates suggest that the more connected tasks are the higher (and more positive) the employment change of an occupation has been. For the task-occupation wage differential we find no effects. In column (2) we present the results when adding the average level of education in an occupation at the start of the regression period and the log of the level of employment in each occupation. The results remain similar, although the effect of task-occupation connectivity doubles in terms of magnitude. Now a one standard deviation change in task-occupation connectivity increases occupational employment by 0.153 of a standard deviation. The next two columns present the results of a weighted least squares approach. This set of estimates points at two developments. First, tasks that are well-connected have experienced positive employment changes. This is consistent with the notion that the least connected tasks are more likely to be separated from a worker's job. Second, tasks with larger wage-differentials have experienced no significant employment changes in the OLS regressions and correlate positively with employment changes in the WLS

\footnotetext{
13 The issue of causality might be a problem here too (see footnote 12 ).
} 
Table 3 Explaining changes in occupation employment by task-occupation connectivity and task-occupation wage differentials

\begin{tabular}{lccccc}
\hline Dependent variable: Change in employment (1996-2005) & $(1)$ & $(2)$ & $(3)$ & $(4)$ \\
& OLS & OLS & WLS & WLS \\
\hline Task-occupation connectivity & $0.075 * *$ & $0.153 * * *$ & $0.058 * *$ & $0.075 * *$ \\
& $(0.030)$ & $(0.048)$ & $(0.023)$ & $(0.032)$ \\
Task-occupation wage differential & 0.003 & 0.032 & $0.067 * *$ & $0.083 * * *$ \\
& $(0.024)$ & $(0.026)$ & $(0.026)$ & $(0.028)$ \\
Education 1996 & & -0.084 & & -0.011 \\
& & $(0.059)$ & $(0.044)$ \\
Log employment 1996 & & 0.029 & & 0.031 \\
& & $(0.027)$ & $(0.022)$ \\
Constant & 0.012 & -0.173 & $0.053 * *$ & -0.183 \\
& $(0.029)$ & $(0.189)$ & $(0.021)$ & $(0.176)$ \\
Observations & 36 & 36 & 36 & 36 \\
$R$-squared & 0.168 & 0.273 & 0.329 & 0.370 \\
\hline
\end{tabular}

Note Robust standard errors in parentheses. The standard errors in the weighted least squares estimations in columns (3) and (4) are clustered at the occupation level. *** $p<0.01$, ** $p<0.05$, * $p<0.10$. The dependent variable is the percentage change in occupational employment between 1996 and 2005. Task-occupation connectivity and task-occupation wage differentials are averages of all available years in our database by occupation and weighted by the importance of each task in an occupation

setting. This suggests that although these tasks have a higher probability to be separated from occupations, this does not necessarily imply that they lose in terms of employment. The pattern of contestability at the task level in Fig. 3 is consistent with this observation.

The next step is to investigate the effects of connectivity of tasks at the industry-task level on employment changes within occupations. Since we assume that there are no inter-industry wage differentials, the variable of interest is task-industry connectivity. We run a number of regressions to see whether there is a correlation between employment changes and task-industry connectivity. We do so by regressing task connectivity and a number of control variables on occupational employment changes in the period 1996-2005. Table 4 presents the estimation results. Similar to the results present in Table 3, task-industry connectivity contributes to positive changes in employment in the period 1996-2005. This is both true for the OLS and WLS regressions and for a number of different specifications.

Finally, a similar regression analysis at the spatial level confirms the pattern of findings in Tables 3 and 4. Spatial occupation concentration is negatively correlated with occupational employment changes, while occupation-space connectivity relates positively to employment change. Table 5 shows these regression results in two specifications. The first column presents the results of a simple regression analysis in which we explain changes in employment between 1996 and 2005 with spatial occupation concentration and occupation-space connectivity and a number of usual suspects. The second column documents the estimates when we weight by occupation size. The 
Table 4 Explaining changes in occupation employment by task-industry connectivity

\begin{tabular}{llccc}
\hline Dependent variable: Change in employment (1996-2005) & $(1)$ & $(2)$ & $(3)$ & $(4)$ \\
& OLS & OLS & WLS & WLS \\
\hline Task-industry connectivity & $0.084 * * *$ & $0.102 * * *$ & $0.081 * * *$ & $0.074 * *$ \\
& $(0.022)$ & $(0.032)$ & $(0.021)$ & $(0.033)$ \\
Education 1996 & & -0.006 & & 0.011 \\
& & $(0.043)$ & 0.034 & $(0.053)$ \\
Log employment 1996 & & $(0.024)$ & 0.003 \\
Constant & & -0.212 & 0.031 & 0.014 \\
& 0.012 & $(0.019)$ \\
Observations & $(0.028)$ & $(0.163)$ & $(0.026)$ & $(0.152)$ \\
$R$-squared & 36 & 36 & 36 & 36 \\
\hline
\end{tabular}

Note Robust standard errors in parentheses. The standard errors in the weighted least squares estimations in columns (3) and (4) are clustered at the occupation level. *** $p<0.01$, ** $p<0.05$, * $p<0.10$. The dependent variable is the percentage change in employment from 1996 to 2005 . Task-industry connectivity is calculated by aggregating the task-industry connectivity across occupations and weighing the numbers by the industry employment share within each occupation (Eq. (3) in the main text)

results of these two exercises are similar. The fact that we do not find significant coefficients for occupation-space connectivity might be caused by the fact that we have been able to include only 17 different regions in the Netherlands in the analysis. The final two columns repeat the analysis without our measures of concentration and connectivity. The explanatory power of these analyses is much lower, while the coefficients on the covariates education and log wages in 1996 remain similar. The effect of log employment in 1996 cannot be distinguished from zero here, while it has a small and negative effect when including concentration and connectivity.

Together the estimates in Tables 3-5 suggest that our measures correlate with occupational employment changes consistent with the framework of the division of labour developed above.

\subsection{Explanatory Power}

We explore the economic meaning of these results by expressing the contribution of task-occupation connectivity and task-occupation wage differentials to the changes in occupational employment over the last decade. The results of this exercise are documented in Fig. 8a. This figure presents a scatter plot of the actual change in occupational employment and the predicted change for each occupation in the database. A similar picture for the industry-level analysis is presented in Fig. $8 \mathrm{~b}$ and for the spatial level in Fig. 8c. We have added a 45-degree line along with a regression line to give an impression of the average predictions of our approach. Ideally all points would be on the 45-degree line.

The regression line in Fig. 8a reveals that we overestimate the occupational employment changes when there are employment losses and do a good job when we predict 
Table 5 Explaining changes in occupation employment by spatial occupation concentration and occupation-space connectivity

\begin{tabular}{lccll}
\hline $\begin{array}{l}\text { Dependent variable: changes in employment } \\
(1996-2005)\end{array}$ & $(1)$ & $(2)$ & $(3)$ & $(4)$ \\
\hline Spatial occupation concentration & OLS & WLS & OLS & WLS \\
\hline Occupation-space connectivity & $-0.142 * *$ & $-0.135 * *$ & & \\
& $(0.069)$ & $(0.058)$ & & \\
Education 1996 & 0.039 & 0.029 & & \\
& $(0.034)$ & $(0.029)$ & & \\
Log employment 1996 & $0.102 * * *$ & $0.133 * * *$ & $0.118 * * *$ & $0.154 * * *$ \\
& $(0.037)$ & $(0.031)$ & $(0.034)$ & $(0.034)$ \\
Log wage 1996 & -0.049 & -0.017 & 0.020 & 0.025 \\
& $(0.043)$ & $(0.027)$ & $(0.025)$ & $(0.019)$ \\
Constant & $-0.326 * * *$ & $-0.285 * * *$ & $-0.326 * * *$ & $-0.333 * * *$ \\
& $(0.113)$ & $(0.091)$ & $(0.102)$ & $(0.093)$ \\
observations & $3.078 * * *$ & $2.276 * * *$ & $2.373 * *$ & $2.390 * * *$ \\
$R$-squared & $(0.966)$ & $(0.720)$ & $(0.880)$ & $(0.717)$ \\
\hline
\end{tabular}

Note Robust standard errors in parentheses. Weighted Least Squares (WLS) standard errors are clustered at the occupation level. *** $p<0.01$, ** $p<0.05, * p<0.10$. The dependent variable is the percentage change in employment from 1996 to 2005 . All variables are standardised such that mean is 0 and variance is 1 . Spatial occupation concentration is the geographic concentration index that measures the degree of job concentration in a region adjusted by population shares (Eq. 4). Occupation-space connectivity measures how jobs are connected at the regional level (Eq. 5). See the text in Sect. 4 for further explanation

employment growth. This seems consistent with Fig. 3 in which we plot contestability. There, some jobs are extremely contestable according to our measures, but have experienced employment growth over the last decade. These are by and large the same occupations for which we predict employment deterioration in Fig. 8a. The predicted changes in Fig. 8b are relatively good. We only understate some effects towards the high-growth occupations. The same argument goes for our predictions at the spatial level in Fig. 8c.

What is interesting to note is that we are most off when jobs consist of relatively many routine tasks, such as elementary occupations and low-skilled service occupations. According to our measures these jobs could be outsourced because they do not connect very well at the worker and industry level. However, at the spatial level we are fairly good at predicting employment changes in these occupations. In addition, our measures do not predict changes in public sector jobs very well. For example, the employment growth of teachers and public sector caring and medical jobs is not very well predicted by our measures.

In the Data Appendix we provide a list of all occupations and our predictions at the different levels of aggregation. 
(a)

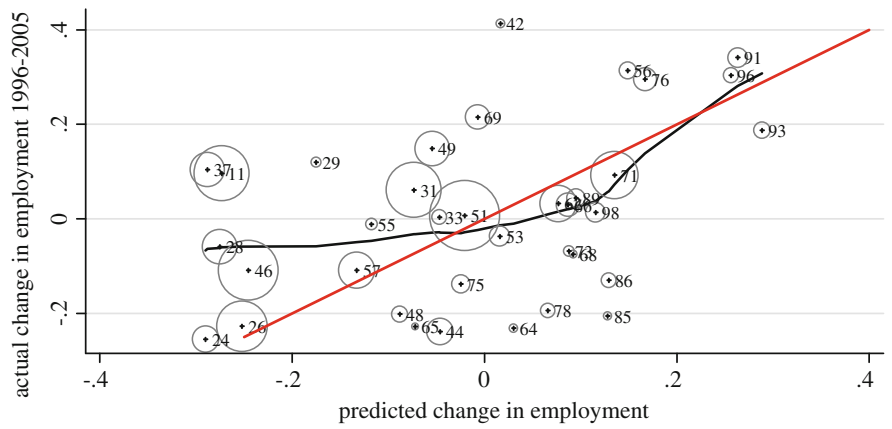

(b)

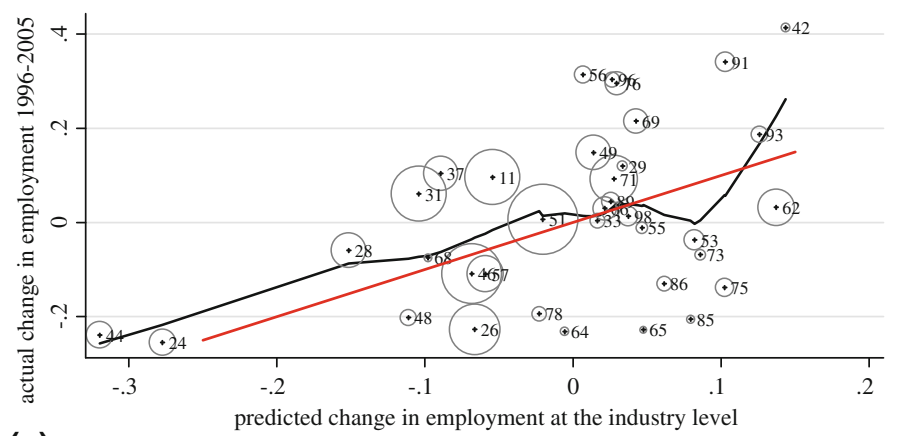

(c)

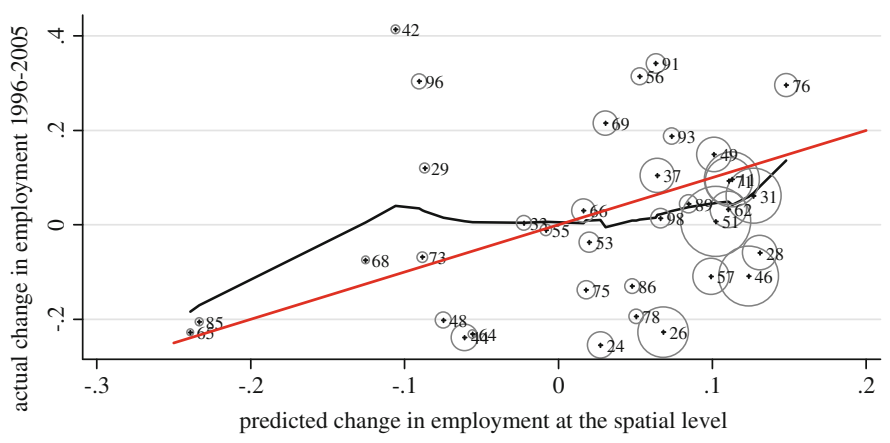

Fig. 8 Predicting changes in occupational employment (1996-2005) along the three measures of the division of labour

\subsection{Offshoring}

The final step of the empirical analysis is to estimate the relationship between offshoring and spatial occupation concentration and occupation-space connectivity. Figures $9 \mathrm{a}, \mathrm{b}$ present scatter plots of the relationship between our measures of offshoring and concentration and connectivity. For spatial occupation concentration Fig. 9a suggests that job concentration is positively correlated to changes in offshoring. So, it seems to be the case that more concentrated jobs have been more contestable since 

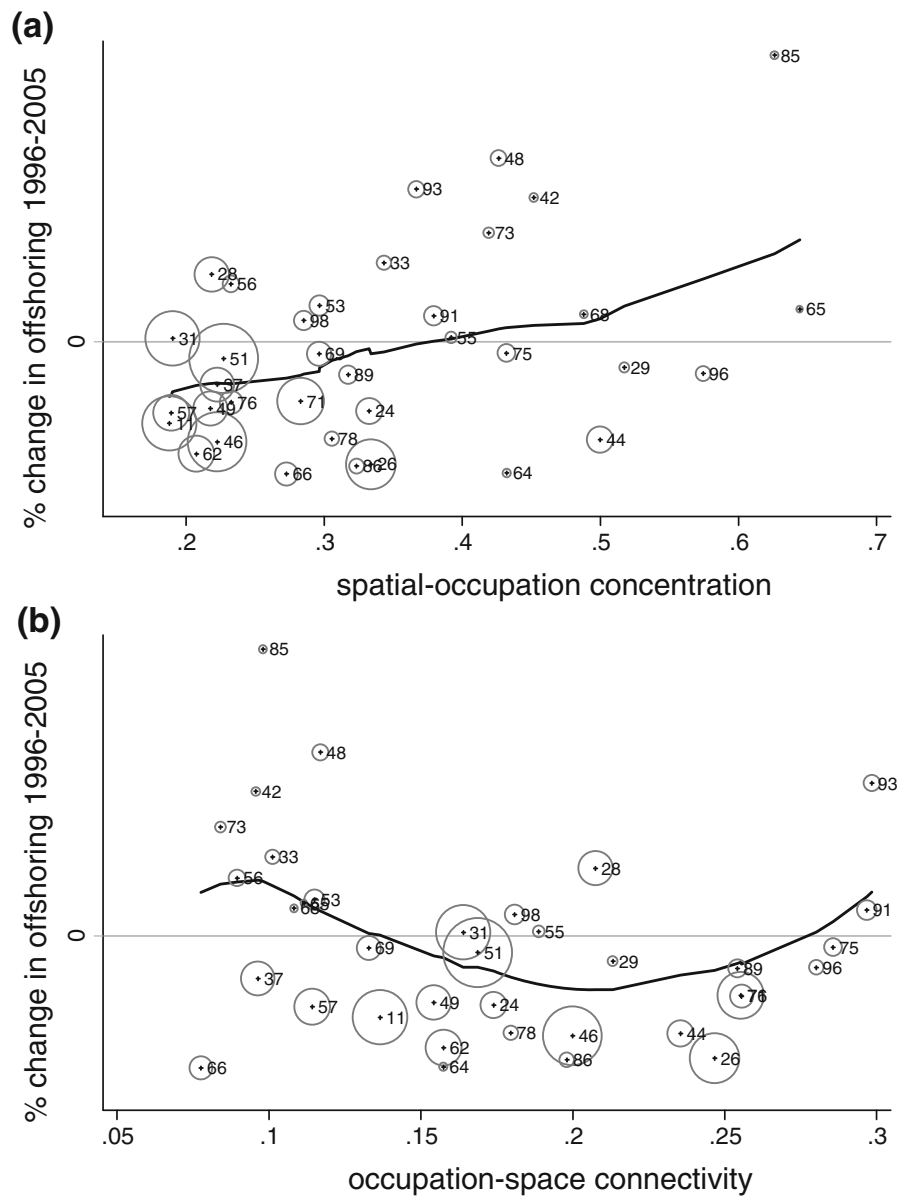

Fig. 9 The effects of spatial occupation concentration and occupation-space connectivity on changes in offshoring, 1996-2005. Note The unit of observation is occupations. The measures of spatial occupation concentration and occupation-space connectivity are defined in Eqs. (4) and (5). Offshoring is defined in Eq. (6)

1996. Figure $9 \mathrm{~b}$ plots the correlation between changes in offshoring and job connectivity. Although eyeball econometrics would suggest a negative correlation between these two variables, the pattern is not very clear. We expect more connected jobs to be less contestable. When we exclude two observation (high-level economic jobs (91) and high-level legal jobs (93) the relationship is indeed negative, and significantly so. Both figures are consistent with the evidence on the contestability measure in Fig. 6.

The patterns present in these pictures are confirmed by a regression analysis in which we try to explain offshoring by concentration and connectivity and a number of covariates. Table 6 lists the results of this regression analysis. The dependent variable is the change in offshoring. The independent variables are concentration, connectivity and the level of offshoring in 1996. When we carry out the analysis at the individual 
Table 6 Explaining changes in offshoring by spatial job connectivity and spatial job concentration

\begin{tabular}{lcccc}
\hline $\begin{array}{l}\text { Dependent variable: Changes in offshoring } \\
(1996-2005)\end{array}$ & $(1)$ & $(2)$ & $(3)$ & $(4)$ \\
\hline Spatial occupation concentration & OLS & OLS & OLS & WLS \\
Occupation-space connectivity & $0.059 * *$ & & $0.060 * *$ & 0.029 \\
& $(0.025)$ & & $(0.023)$ & $(0.023)$ \\
Offshoring 1996 & & -0.020 & -0.021 & -0.005 \\
& & $(0.015)$ & $(0.013)$ & $(0.012)$ \\
Constant & $-0.023 *$ & -0.014 & $-0.023 *$ & $-0.022 * *$ \\
& $(0.012)$ & $(0.085)$ & $(0.011)$ & $(0.010)$ \\
Observations & $0.024 *$ & 0.017 & $0.024 *$ & 0.007 \\
$R$-squared & $(0.014)$ & $(0.013)$ & $(0.013)$ & $(0.015)$ \\
\hline
\end{tabular}

Note Robust standard errors in parentheses. Weighted Least Squares (WLS) standard errors are clustered at the occupation level. $* * * p<0.01$, $* * p<0.05, * p<0.10$. The dependent variable is the percentage change in offshoring (embodied imports) from 1996 to 2005. All variables are standardised such that mean is 0 and variance is 1 . Spatial occupation concentration is the geographic concentration index that measures the degree of job concentration in a region adjusted by population shares (Eq. 4). Occupation-space connectivity measures how jobs are connected at the regional level (Eq. 5). See the text in Sect. 4 for further explanation

worker level and at the industry level, we obtain insignificant estimates. This suggests that offshoring is best explained at the spatial level of the division of labour.

\section{Conclusions and Policy Implications}

The main goal of this paper has been to develop measures of division of labour and to document and understand trends in the unbundling of tasks in the Netherlands in the period 1996-2005. We have shown that looking at current trends in the structure of employment can be understood from a framework of the division of labour across tasks. It is important to distinguish three levels of aggregation at which developments take place: the individual level, the industry level and the spatial level. An important conclusion is that globalisation has not affected all the work, but only specific tasks and occupations that have been most contestable, whereas others remained relatively unaffected.

Specifically, the analyses in this paper show that in the period 1996-2005 there has been a tendency of unbundling tasks in the Netherlands. When thinking about the threat of offshoring for employment in the Netherlands, it has to be kept in mind that not every occupation and not every task in every occupation is subject to the process of unbundling and this wave of globalisation. Our indicators show determinants of task unbundling and potential offshoring. They are able to document which tasks and which occupations might be contestable and which are not. At the same time, and based on the same logic, this type of globalisation also offers opportunities for the Netherlands 
to inshore tasks. That is why we also find some tasks and occupations to be growing (in terms of employment shares) over time, which is a sign of comparative strength of the Netherlands. For policy makers this finding is of interest because it suggests that a deeper understanding of the division of labour is important to understand recent changes in occupational employment. Shrinking and growing occupations could tell different stories: it could be about the gains from specialisation, outsourcing of work to other firms or even offshoring abroad. A clear view on the dominant effect helps to develop effective policies.

When looking at the kinds of tasks that are relatively easily unbundled from the task bundle of an individual worker, our analyses reveal that especially physical tasks are not very connected to other tasks. In general these tasks can be carried out by other workers whose earnings are substantially lower. Some less obvious tasks seem to be contestable as well. For example, selling, doing statistical analysis and performing calculations are tasks observed to be relatively less connected to others tasks. For a task such as giving speeches there is a relatively large comparative advantage that can be obtained from specialisation in this task. Possibilities for unbundling at the individual level are the main restriction for unbundling at the industry level. Especially for the statistical and calculation tasks, connectivity at the industry level is higher than at the individual level. This limits the possibilities to outsource this work to other firms, although it can easily be taken out of the bundle of tasks of the individual worker. At the spatial level, research in math and science is the most obvious example of work that could be easily moved to other places: There is not strong link to the location of the customers and this work is not strongly connected to other economic activities. Also agriculture, transport and remarkably some safety occupation fall into this category.

The analyses show that unbundling accounts for substantial changes in the employment shares of occupations and accounts for-especially at the spatial level-a substantial share of the increase in offshoring of activities abroad. While some occupations lost employment and offshoring increased, other occupations gained in terms of employment shares. This indicates that international developments are important for determining Dutch task bundles, and not just that the Netherlands has lost employment. There is a restructuring of employment rather than a loss of employment.

For individual tasks the low-educated workers are faced with this loss of employment, while high-educated workers seem to gain. Since unbundling at the individual level and unbundling at the industry level are highly correlated, this also holds for the industry developments. At the spatial level the story is different though. Since the link between production and the customer has a stronger influence on employment changes and offshoring than job connectivity, here the low-educated gain from their position. Offshoring tasks such as cleaning and other types of low-skilled service tasks seem to be impossible.

Overall there is no strong sign of polarisation of the Dutch labour market as observed in the United States in the 1990s. If anything, polarisation has taken place across regions. To strengthen the Dutch labour market, thinking in terms of the connectivity of activities at the spatial level can be a very effective approach. In the Netherlands the Randstad region and the region of Eindhoven have grown in the past decades. They have become the most important centres of productivity and employment, most likely because of tendencies for certain tasks and occupations to cluster together. An 
interesting policy challenge is to see whether also in other regions of the country clusters of tasks are likely to emerge. Such clusters are able to reduce the contestability of economic activities and resist the strong forces of globalisation. For such policies to be successful it is important to focus on bundles of complementary tasks instead of traditional industry clusters and to acknowledge that offshoring of some activities leads to the inshoring of other tasks. This requires sound information about the Dutch division of labour. In this paper we had to rely on British tasks data. The collection of data for the Dutch labour market about employment in terms of tasks is very important to gain more insight in current and future labour-market developments in the Netherlands.

\section{Data Appendix}

See Table 7, 8, 9, 10, 11, 12, 13, 14, 15.

Table 7 Variable definitions

Variable Definition

Worker

Task 1996-2005

Task 1996-2001

Task 2001-2005

Task importance 1996 (2001)

Task-occupation connectivity 1996 (2001)

Task-occupation wage differential 1996 (2001)

Contestability

Task-occupation connectivity

Task-occupation wage differential
Difference in task importance between BSS 1997 and BSS 2006 (Occupation-task specific). Source: BSS and EBB

Difference in task importance between BSS 1997 and BSS 2001 (Occupation-task specific). Source: BSS and EBB

Difference in task importance between BSS 2001 and BSS 2006 (Occupation-task specific). Source: BSS and EBB

Occupation-task specific task importance within an occupation class for 1996 (2001). Source: British Skills Survey (BSS) 1997 (2001)

Occupation task specific index that measures the connectedness of a task to other tasks in 1996 (2001). See Eq. (2). Source BSS and EBB

Absolute value of the difference between occupation and task wages in 1996 (2001). The earliest wage information that is available for Dutch occupation classes is for 1999. Therefore 1999 wages are used. Task wages are calculated by multiplying the wage by task importance (weight is $\left[\begin{array}{lllll}0 & 1 & 2 & 3 & 4\end{array}\right]$ from least important to most important) at the individual level and then calculating averages by Dutch occupation classes. See Eq. (1) and the corresponding explanation. Source: EBB, SSB and BSS.

Contestability measuring offshorability calculated as task-occupation wage differential minus task-occupation connectivity. Source: BSS

Occupation specific measure obtained by weighting task-occupation connectivity by task importance and aggregating over occupations. Average of three years 1996, 2001 and 2005. Source: BSS

Occupation specific measure obtained by weighting the task-occupation specific wage differential by task importance and aggregating over occupations. Average of three available years 1996, 2001 and 2005. Source BSS 
Table 7 continued

\begin{tabular}{|c|c|}
\hline Variable & Definition \\
\hline \multicolumn{2}{|l|}{ Industry } \\
\hline $\begin{array}{l}\text { Task-industry } \\
\text { connectivity } 1996 \\
(2001)\end{array}$ & $\begin{array}{l}\text { Industry-task specific index that measures the connectedness of a } \\
\text { task to other tasks in } 1996 \text { (2001). See Eq. (3). Source BSS 1997, } \\
\text { 2001, } 2006 \text { and EBB }\end{array}$ \\
\hline $\begin{array}{l}\text { Task-industry } \\
\text { connectivity }\end{array}$ & $\begin{array}{l}\text { Occupation specific measure obtained by aggregating the } \\
\text { task-industry specific connectivity over industries and merging to } \\
\text { occupation-industry data. We aggregate task-industry } \\
\text { connectivity over occupations by weighting it by the share of } \\
\text { industry employment within each occupation. The result is an } \\
\text { occupation specific measure. Average of three years 1996, } 2001 \\
\text { and 2005. Source: BSS, EBB }\end{array}$ \\
\hline \multicolumn{2}{|r|}{ 然 } \\
\hline $\begin{array}{l}\text { Spatial occupation } \\
\text { concentration (soc) }\end{array}$ & $\begin{array}{l}\text { Occupation specific index measuring spatial job concentration } \\
\text { adjusted by population share of the region. We used RBA } \\
\text { definition that divides the Netherlands in } 17 \text { regions. See Eq. (4) } \\
\text { and the corresponding explanation. Source: EBB } 1996\end{array}$ \\
\hline $\begin{array}{l}\text { Occupation-space } \\
\text { connectivity (osc) }\end{array}$ & $\begin{array}{l}\text { Index that measures job connectivity at the regional level. We used } \\
\text { RBA definition that divides the Netherlands in } 17 \text { regions. See } \\
\text { Eq. (5) and the corresponding explanation. Source: EBB } 1996\end{array}$ \\
\hline Offshoring 1996 & $\begin{array}{l}\text { Level of offshoring in } 1996 \text { that shows the amount of imported } \\
\text { inputs needed to produce one unit of output taking all embodied } \\
\text { imports into account. The numbers are then merged to individual } \\
\text { level data such that every individual in the same industry class } \\
\text { has the same value and then aggregated over 2-digit occupations. } \\
\text { Source. Input-Output tables of the Netherlands, CBS }\end{array}$ \\
\hline $\begin{array}{l}\text { Change in offshoring } \\
\text { 1996-2005 }\end{array}$ & $\begin{array}{l}\text { Percentage change in offshoring from } 1996 \text { to } 2005 \text {. Offshoring } \\
\text { measure is calculated as above. Source. Input-Output tables of } \\
\text { Netherlands, CBS }\end{array}$ \\
\hline \multicolumn{2}{|l|}{ Other variables } \\
\hline Education 1996 & Education level for each occupational class in 1996. Source EBB \\
\hline Log employment 1996 & $\begin{array}{l}\text { Log of employment for each occupational class in } 1996 . \text { Head } \\
\text { count, people who worked more than } 12 \mathrm{~h} \text {. Source EBB. }\end{array}$ \\
\hline Log wage 1996 & $\begin{array}{l}\text { Log of wage for each occupational class in } 1996 \text {. Wages measured } \\
\text { as average per person with a job. Source: SSB }\end{array}$ \\
\hline $\begin{array}{l}\text { Change in employment, } \\
\text { 1996-2005 }\end{array}$ & Percentage change in employment 1996-2005. Source: EBB \\
\hline
\end{tabular}

Table 8 Summary statistics

\begin{tabular}{|c|c|c|c|c|}
\hline Variable & Mean & SD & Min & Max \\
\hline \multicolumn{5}{|l|}{ Worker } \\
\hline Task importance 1996 & 3.550 & 0.90 & 1.00 & 5.00 \\
\hline Task importance 2001 & 3.605 & 0.81 & 1.16 & 5.00 \\
\hline Task importance 2005 & 3.652 & 0.82 & 1.24 & 5.00 \\
\hline Task 1996-2005 & 0.102 & 0.41 & -1.66 & 2.24 \\
\hline Task 1996-2001 & 0.055 & 0.41 & -1.73 & 2.74 \\
\hline Task 2001-2005 & 0.046 & 0.29 & -1.17 & 1.11 \\
\hline Task-occupation connectivity 1996 & 0.226 & 0.07 & 0.029 & 0.334 \\
\hline
\end{tabular}


Table 8 continued

\begin{tabular}{|c|c|c|c|c|}
\hline Variable & Mean & SD & Min & Max \\
\hline Task-occupation connectivity 2001 & 0.204 & 0.06 & 0.036 & 0.304 \\
\hline Task-occupation connectivity 2005 & 0.209 & 0.07 & 0.041 & 0.314 \\
\hline Task-occupation wage differential 1996 & 708.99 & 526.23 & 0.34 & 2724.42 \\
\hline Task-occupation wage differential 2001 & 830.91 & 651.41 & 1.34 & 3418.18 \\
\hline Task-occupation connectivity & 0.0066 & 0.0002 & 0.0060 & 0.0071 \\
\hline Task-occupation wage differential & 22.91 & 16.03 & 2.23 & 72.30 \\
\hline Contestability & 0.051 & 1.304 & -2.11 & 3.12 \\
\hline \multicolumn{5}{|l|}{ Industry } \\
\hline Task importance 1996 & 3.360 & 0.793 & 1.00 & 5.00 \\
\hline Task importance 2001 & 3.464 & 0.784 & 1.00 & 5.00 \\
\hline Task importance 2005 & 3.536 & 0.742 & 1.00 & 5.00 \\
\hline Task 1996-2005 & 0.176 & 0.493 & -2.77 & 4.00 \\
\hline Task 1996-2001 & 0.102 & 0.527 & -4.00 & 4.00 \\
\hline Task 2001-2005 & 0.071 & 0.480 & -3.05 & 2.72 \\
\hline Task-industry connectivity 1996 & 0.313 & 0.109 & 0.034 & 0.481 \\
\hline Task-industry connectivity 2001 & 0.293 & 0.121 & 0.017 & 0.505 \\
\hline Task-industry connectivity 2005 & 0.285 & 0.101 & 0.034 & 0.469 \\
\hline Task-industry connectivity & 0.299 & 0.004 & 0.287 & 0.305 \\
\hline \multicolumn{5}{|l|}{ Spatial } \\
\hline Spatial occupation concentration & 0.344 & 0.125 & 0.187 & 0.644 \\
\hline Occupation space connectivity & 0.173 & 0.067 & 0.078 & 0.298 \\
\hline Offshoring 1996 & 0.128 & 0.048 & 0.041 & 0.225 \\
\hline Change in offshoring 1996-2005 & 0.015 & 0.080 & -0.087 & 0.259 \\
\hline Change in employment 1996-2005 & 0.008 & 0.184 & -0.255 & 0.413 \\
\hline Log employment 1996 & 6.60 & 1.26 & 4.35 & 9.00 \\
\hline Education 1996 & 3.35 & 0.82 & 2.09 & 4.89 \\
\hline Log wage 1996 & 7.64 & 0.33 & 6.99 & 8.19 \\
\hline
\end{tabular}

Table 9 List of task in BSS

\begin{tabular}{ll}
\hline Task & Importance of task \\
\hline Detail & Paying close attention to detail \\
People & Dealing with people \\
Peach & Teaching people (individuals or groups) \\
Speech & Making speeches/presentations \\
Persuad & Persuading or Influencing others \\
Selling & Selling a product or service \\
Caring & Counselling, advising or caring for customers or clients \\
Strength & Physical strength (e.g., to carry, push or pull heavy objects) \\
Stamina & physical stamina (e.g., to work for long periods on physical activities) \\
\hline
\end{tabular}


Table 9 List of task in BSS

\begin{tabular}{|c|c|}
\hline Task & Importance of task: \\
\hline Hands & Skill or accuracy in using hands/fingers (e.g., to mend or repair, assemble etc.) \\
\hline Tools & Knowledge of use or operation of tools/equipment machinery) \\
\hline Product & Knowledge of particular products or services \\
\hline Special & Specialist knowledge or understanding \\
\hline Orgwork & Knowledge of how organisation works \\
\hline Faults & Spotting problems or faults (in your own work or somebody else's work) \\
\hline Cause & Working out cause of problems/faults (in your own work or somebody else's work) \\
\hline Solutn & Thinking of solutions to problems (in your own work or Somebody Else's work) \\
\hline Analyse & Analysing complex problems in depth \\
\hline Noerror & Checking things to ensure no errors (in your own work or somebody else's work) \\
\hline Mistake & Noticing when there is a mistake (in your own work or somebody else's work) \\
\hline Panme & Planning own activities \\
\hline Planoth & Planning the activities of others \\
\hline Mytime & Organising own time \\
\hline Ahead & Thinking ahead \\
\hline Read & Reading written information (e.g., forms, notices and signs) \\
\hline Short & Reading short documents such as reports, letters or memos? \\
\hline Long & Reading long documents such as long reports, manuals, articles or books \\
\hline Write & writing materials such as forms, notices and signs \\
\hline Writesh & Writing short documents (e.g., reports, letters or memos) \\
\hline Writelg & Writing long documents with correct spelling and grammar \\
\hline Calca & Adding, subtracting, multiplying and dividing numbers \\
\hline Percent & Calculations using decimals, percentages or fractions \\
\hline Stats & Calculations using more advanced mathematical or statistical procedures \\
\hline
\end{tabular}

Table 10 Most and least connected tasks according to task-occupation connectivity (ranked by 2005 score)

\begin{tabular}{llll}
\hline & $\begin{array}{l}\text { Task-occupation } \\
\text { connectivity 1996 }\end{array}$ & $\begin{array}{l}\text { Task-occupation } \\
\text { connectivity 2005 }\end{array}$ & $\begin{array}{c}\text { Difference } \\
1996-2005\end{array}$ \\
\hline Analyse & 0.308 & 0.296 & -0.012 \\
Writesh & 0.284 & 0.284 & 0.001 \\
Long & 0.302 & 0.284 & -0.018 \\
Short & 0.278 & 0.283 & 0.005 \\
Solutn & 0.312 & 0.280 & -0.032 \\
Writelg & 0.290 & 0.267 & -0.023 \\
Ahead & 0.273 & 0.260 & -0.013 \\
Special & 0.269 & 0.251 & -0.018 \\
Persuad & 0.268 & 0.248 & -0.020 \\
Cause & 0.279 & 0.246 & -0.033 \\
Planoth & 0.255 & 0.238 & -0.018 \\
Write & 0.226 & 0.237 & 0.011 \\
\hline
\end{tabular}


Table 10 continued

\begin{tabular}{llll}
\hline & $\begin{array}{l}\text { Task-occupation } \\
\text { connectivity 1996 }\end{array}$ & $\begin{array}{l}\text { Task-occupation } \\
\text { connectivity 2005 }\end{array}$ & $\begin{array}{l}\text { Difference } \\
1996-2005\end{array}$ \\
\hline Noerror & 0.260 & 0.237 & -0.023 \\
Planme & 0.263 & 0.235 & -0.028 \\
Mytime & 0.242 & 0.235 & -0.007 \\
Mistake & 0.252 & 0.235 & -0.017 \\
Orgwork & 0.232 & 0.234 & 0.002 \\
Speech & 0.241 & 0.234 & -0.007 \\
Faults & 0.250 & 0.232 & -0.018 \\
Read & 0.231 & 0.230 & -0.001 \\
Teach & 0.241 & 0.226 & -0.016 \\
Listen & 0.223 & 0.223 & 0.000 \\
Usepc & 0.184 & 0.195 & 0.011 \\
Caring & 0.193 & 0.191 & -0.002 \\
Teamwk & 0.181 & 0.190 & 0.009 \\
People & 0.190 & 0.184 & -0.006 \\
Detail & 0.200 & 0.184 & -0.017 \\
Percent & 0.221 & 0.175 & -0.046 \\
Stats & 0.185 & 0.171 & -0.015 \\
Product & 0.214 & 0.165 & -0.049 \\
Calca & 0.183 & 0.141 & -0.043 \\
Selling & 0.155 & 0.105 & -0.050 \\
Tools & 0.089 & 0.086 & -0.004 \\
Hands & 0.075 & 0.074 & -0.001 \\
Stamina & 0.053 & 0.068 & 0.015 \\
Strengt & 0.042 & 0.055 & 0.013 \\
\hline & & & \\
\hline
\end{tabular}

Table 11 Task-occupation connectivity and task-occupation wage differential by occupation

\begin{tabular}{llllc}
\hline NLSBC92 code & Occupation & $\begin{array}{l}\text { Task-occupation } \\
\text { connectivity 1996 }\end{array}$ & $\begin{array}{l}\text { Task-occupation } \\
\text { connectivity 2005 }\end{array}$ & $\begin{array}{l}\text { Task-occupation } \\
\text { wage differential } \\
1999\end{array}$ \\
\hline 11 & Elementary occupations & 0.216 & 0.201 & 909.9 \\
24 & Agricultural (low) & 0.214 & 0.202 & 488.3 \\
26 & Technical (low) & 0.218 & 0.204 & 287.3 \\
28 & Transport (low) & 0.216 & 0.204 & 380.4 \\
29 & (Para) medical (low) & 0.218 & 0.206 & 855.8 \\
31 & Administrative, & 0.225 & 0.207 & 813.7 \\
& $\quad$ commercial, & & & \\
33 & economic (low) & 0.225 & 0.210 & 179.4 \\
37 & Security (low) & 0.215 & 0.201 & 1116.7 \\
42 & Care taking (low) & 0.228 & 0.210 & 463.5 \\
\hline
\end{tabular}


Table 11 continued

NLSBC92 code occupation Task-occupation Task-occupation Task-occupation connectivity 1996 connectivity 2005 wage differential 1999

\begin{tabular}{|c|c|c|c|c|}
\hline 44 & Agricultural (medium) & 0.233 & 0.207 & 415.4 \\
\hline 46 & Technical (medium-low) & 0.219 & 0.204 & 164.4 \\
\hline 48 & Transport (medium) & 0.225 & 0.209 & 116.8 \\
\hline 49 & $\begin{array}{l}\text { (Para) medical } \\
\text { (medium-low) }\end{array}$ & 0.226 & 0.208 & 669.5 \\
\hline 51 & $\begin{array}{l}\text { Administrative, } \\
\text { commercial, } \\
\text { economic } \\
\text { (medium-low) }\end{array}$ & 0.227 & 0.211 & 146.2 \\
\hline 53 & Security (medium-low) & 0.226 & 0.213 & 346.7 \\
\hline 55 & Linguistic, cultural (low) & 0.223 & 0.208 & 381.6 \\
\hline 56 & $\begin{array}{l}\text { Societal, } \\
\text { governmental } \\
\text { (medium) }\end{array}$ & 0.231 & 0.215 & 517.8 \\
\hline 57 & Care taking (medium) & 0.221 & 0.207 & 718.8 \\
\hline 62 & Teachers (medium) & 0.230 & 0.213 & 76.1 \\
\hline 64 & Agricultural (high) & 0.230 & 0.210 & 599.0 \\
\hline 65 & Scientific (medium) & 0.223 & 0.208 & 225.0 \\
\hline 66 & $\begin{array}{l}\text { Technical } \\
\text { (medium-high) }\end{array}$ & 0.228 & 0.213 & 813.8 \\
\hline 68 & Transport (high) & 0.226 & 0.211 & 2478.8 \\
\hline 69 & $\begin{array}{l}\text { (Para) medical } \\
\text { (medium-high) }\end{array}$ & 0.227 & 0.210 & 427.3 \\
\hline 71 & $\begin{array}{l}\text { Administrative, } \\
\text { commercial, } \\
\text { economic } \\
\text { (medium-high) }\end{array}$ & 0.231 & 0.214 & 750.6 \\
\hline 73 & $\begin{array}{l}\text { Security } \\
\text { (medium-high) }\end{array}$ & 0.231 & 0.212 & 945.7 \\
\hline 75 & Linguistic, cultural (high) & 0.228 & 0.210 & 177.1 \\
\hline 76 & $\begin{array}{l}\text { Societal, } \\
\text { governmental } \\
\text { (medium-high) }\end{array}$ & 0.233 & 0.214 & 188.1 \\
\hline 78 & Managers (medium) & 0.228 & 0.210 & 1445.5 \\
\hline 85 & Scientific (high) & 0.233 & 0.212 & 1194.9 \\
\hline 86 & Technical (high) & 0.230 & 0.213 & 1182.3 \\
\hline 89 & (Para) medical (high) & 0.227 & 0.212 & 1382.6 \\
\hline 91 & $\begin{array}{l}\text { Administrative, } \\
\text { commercial, } \\
\text { economic (high) }\end{array}$ & 0.233 & 0.216 & 1221.1 \\
\hline 93 & Security (high) & 0.234 & 0.218 & 1074.8 \\
\hline 96 & Societal, governmental (high) & 0.232 & 0.218 & 625.6 \\
\hline 98 & Managers (high) & 0.228 & 0.212 & 1743.2 \\
\hline
\end{tabular}


Table 12 Most and least connected tasks according to task-industry connectivity (ranked by 2005 score)

\begin{tabular}{|c|c|c|c|}
\hline Tasks & $\begin{array}{l}\text { Task-industry } \\
\text { connectivity } 1996\end{array}$ & $\begin{array}{l}\text { Task-industry } \\
\text { connectivity } 2005\end{array}$ & $\begin{array}{l}\text { Difference } \\
\text { 1996-2005 }\end{array}$ \\
\hline Analyse & 0.443 & 0.446 & 0.004 \\
\hline Special & 0.428 & 0.427 & -0.001 \\
\hline Short & 0.434 & 0.419 & -0.015 \\
\hline Long & 0.346 & 0.414 & 0.068 \\
\hline Solutn & 0.451 & 0.391 & -0.060 \\
\hline Writesh & 0.413 & 0.361 & -0.052 \\
\hline Persuad & 0.397 & 0.358 & -0.039 \\
\hline Ahead & 0.357 & 0.357 & 0.001 \\
\hline Write & 0.385 & 0.348 & -0.037 \\
\hline Percent & 0.385 & 0.341 & -0.044 \\
\hline Orgwork & 0.305 & 0.336 & 0.031 \\
\hline Speech & 0.414 & 0.335 & -0.080 \\
\hline Mytime & 0.246 & 0.328 & 0.081 \\
\hline Cause & 0.353 & 0.325 & -0.028 \\
\hline Noerror & 0.339 & 0.319 & -0.019 \\
\hline Teach & 0.372 & 0.319 & -0.053 \\
\hline Stats & 0.375 & 0.289 & -0.086 \\
\hline Planme & 0.326 & 0.282 & -0.044 \\
\hline Faults & 0.280 & 0.281 & 0.001 \\
\hline People & 0.274 & 0.280 & 0.007 \\
\hline Mistake & 0.360 & 0.279 & -0.081 \\
\hline Calca & 0.344 & 0.279 & -0.065 \\
\hline Read & 0.345 & 0.276 & -0.069 \\
\hline Caring & 0.193 & 0.245 & 0.052 \\
\hline Writelg & 0.370 & 0.236 & -0.134 \\
\hline Planoth & 0.325 & 0.234 & -0.091 \\
\hline Detail & 0.329 & 0.233 & -0.095 \\
\hline Product & 0.265 & 0.229 & -0.037 \\
\hline Selling & 0.089 & 0.137 & 0.049 \\
\hline Tools & 0.139 & 0.101 & -0.038 \\
\hline Hands & 0.128 & 0.083 & -0.045 \\
\hline Strengt & 0.066 & 0.067 & 0.000 \\
\hline Stamina & 0.065 & 0.059 & -0.005 \\
\hline
\end{tabular}


Table 13 Task-industry connectivity by industry

\begin{tabular}{|c|c|c|c|}
\hline EBB Industry code & Industry & $\begin{array}{l}\text { Task-industry con- } \\
\text { nectivity } 1996\end{array}$ & $\begin{array}{l}\text { Task-industry con- } \\
\text { nectivity } 2005\end{array}$ \\
\hline 1 & Agriculture and fishery & 0.301 & 0.277 \\
\hline 2 & Mining and Quarrying & 0.315 & 0.289 \\
\hline 3 & Manufacturing food products & 0.309 & 0.278 \\
\hline 4 & Manufacture of textiles & 0.309 & 0.277 \\
\hline 5 & Manufacturing of wearing apparel & 0.308 & 0.284 \\
\hline 6 & Manufacture of leather and footwear & 0.292 & 0.275 \\
\hline 7 & Manufacture of wood & 0.303 & 0.279 \\
\hline 8 & Manufacture of paper & 0.312 & 0.281 \\
\hline 9 & Publishing & 0.313 & 0.293 \\
\hline 10 & Extraction and agglomeration of peat & 0.313 & 0.282 \\
\hline 11 & Extraction of crude petroleum and gas & 0.319 & 0.289 \\
\hline 12 & Manufacture, chemicals/ chemical product & 0.324 & 0.288 \\
\hline 13 & Manufacture, rubber/plastic products & 0.304 & 0.280 \\
\hline 14 & Quarrying and winning of sand & 0.307 & 0.276 \\
\hline 15 & Manufacture of basic metals & 0.307 & 0.282 \\
\hline 16 & Manufacture,. fabricated metal products & 0.314 & 0.283 \\
\hline 17 & Machine industry & 0.312 & 0.284 \\
\hline 18 & Manufacturing of electrical machinery & 0.316 & 0.288 \\
\hline 19 & Manufacturing of audio equipment & 0.312 & 0.293 \\
\hline 20 & Manufacturing of medical equipment & 0.318 & 0.285 \\
\hline 21 & Manufacture of motor vehicles & 0.311 & 0.283 \\
\hline 22 & Manufacture of transport equipment & 0.315 & 0.285 \\
\hline 24 & Manufacture of furniture & 0.310 & 0.284 \\
\hline 25 & Energy and water supply & 0.323 & 0.292 \\
\hline 26 & Construction & 0.309 & 0.281 \\
\hline 27 & Building and construction & 0.309 & 0.281 \\
\hline 28 & Building and installation & 0.309 & 0.276 \\
\hline 29 & Sale and repair of motor vehicles & 0.308 & 0.282 \\
\hline 30 & Wholesale agricultural products & 0.313 & 0.283 \\
\hline 31 & Wholesale of food & 0.313 & 0.285 \\
\hline 32 & Wholesale of intermediate goods & 0.313 & 0.283 \\
\hline 33 & Wholesale of machines and equipment & 0.313 & 0.291 \\
\hline 34 & Other wholesale & 0.313 & 0.288 \\
\hline 35 & Retail sale, warehouses and supermarkets & 0.307 & 0.279 \\
\hline 36 & Retail sale, supermarkets in foods & 0.307 & 0.280 \\
\hline 37 & Other retail trade & 0.307 & 0.281 \\
\hline 38 & Hotels and restaurants & 0.305 & 0.277 \\
\hline 39 & Land transport, transport via pipelines & 0.306 & 0.281 \\
\hline 40 & Other transport & 0.306 & 0.281 \\
\hline 41 & Water transport & 0.310 & 0.284 \\
\hline
\end{tabular}


Table 13 continued

\begin{tabular}{|c|c|c|c|}
\hline EBB Industry code & Industry & $\begin{array}{l}\text { Task-industry con- } \\
\text { nectivity } 1996\end{array}$ & $\begin{array}{l}\text { Task-industry con- } \\
\text { nectivity } 2005\end{array}$ \\
\hline 42 & Air transport & 0.321 & 0.283 \\
\hline 43 & Travel agencies and tour operators & 0.317 & 0.290 \\
\hline 44 & Renting of motor vehicles & 0.317 & 0.282 \\
\hline 45 & Post and telecommunications & 0.313 & 0.285 \\
\hline 46 & Financial activities, banks & 0.322 & 0.295 \\
\hline 47 & Insurance and pension funds & 0.325 & 0.297 \\
\hline 48 & Other financial services & 0.324 & 0.294 \\
\hline 49 & Real estate and renting & 0.322 & 0.291 \\
\hline 50 & Computer services, information technology & 0.318 & 0.293 \\
\hline 51 & Research and development & 0.328 & 0.292 \\
\hline 52 & Legal/economic activities & 0.320 & 0.297 \\
\hline 53 & Architectural and engineering activities & 0.320 & 0.292 \\
\hline 55 & Cleaning activities & 0.320 & 0.281 \\
\hline 56 & Other business activities & 0.320 & 0.288 \\
\hline 57 & Public administration & 0.321 & 0.292 \\
\hline 58 & Basic and special education & 0.322 & 0.290 \\
\hline 59 & Secondary education & 0.322 & 0.292 \\
\hline 60 & Higher education & 0.322 & 0.295 \\
\hline 61 & Other education & 0.322 & 0.290 \\
\hline 62 & Hospitals & 0.315 & 0.287 \\
\hline 63 & Other health related services & 0.315 & 0.287 \\
\hline 64 & Nursing and retirement homes & 0.315 & 0.287 \\
\hline 65 & Other self-care activities & 0.315 & 0.287 \\
\hline 66 & Sewage refusal and disposal, sanitation & 0.306 & 0.278 \\
\hline 67 & Activities of membership organisation & 0.321 & 0.293 \\
\hline 68 & Recreational, cultural and sporting activities & 0.311 & 0.285 \\
\hline 69 & Laundry, personal care & 0.307 & 0.277 \\
\hline 70 & Private household activities & 0.299 & 0.276 \\
\hline 71 & Extraterritorial organisations and bodies & 0.310 & 0.292 \\
\hline
\end{tabular}

Table 14 Actual change in employment and predicted values at each stage

\begin{tabular}{llllll}
\hline $\begin{array}{l}\text { NLSBC92 } \\
\text { code }\end{array}$ & Occupation & $\begin{array}{l}\text { Employment } \\
\text { change } \\
1996-2005\end{array}$ & $\begin{array}{l}\text { Prediction } \\
\text { (worker) }\end{array}$ & $\begin{array}{l}\text { Prediction } \\
\text { (industry) }\end{array}$ & $\begin{array}{l}\text { Prediction } \\
\text { (spatial) }\end{array}$ \\
\hline 11 & Elementary occupations & 0.096 & -0.273 & -0.054 & 0.113 \\
24 & Agricultural (low) & -0.255 & -0.290 & -0.277 & 0.027 \\
26 & Technical (low) & -0.227 & -0.252 & -0.066 & 0.068 \\
28 & Transport (low) & -0.059 & -0.275 & -0.151 & 0.131 \\
29 & (Para) medical (low) & 0.120 & -0.175 & 0.033 & -0.087 \\
\hline
\end{tabular}


Table 14 continued

\begin{tabular}{|c|c|c|c|c|c|}
\hline $\begin{array}{l}\text { NLSBC92 } \\
\text { code }\end{array}$ & Occupation & $\begin{array}{l}\text { Employment } \\
\text { change } 1996- \\
2005\end{array}$ & $\begin{array}{l}\text { Prediction } \\
\text {-(worker) }\end{array}$ & $\begin{array}{l}\text { Prediction } \\
\text { (industry) }\end{array}$ & $\begin{array}{l}\text { Prediction } \\
\text { (spatial) }\end{array}$ \\
\hline 31 & $\begin{array}{l}\text { Administrative, } \\
\text { commercial, economic } \\
\text { (low) }\end{array}$ & 0.061 & -0.073 & -0.104 & 0.127 \\
\hline 33 & Security (low) & 0.004 & -0.047 & 0.017 & -0.022 \\
\hline 37 & Care taking (low) & 0.104 & -0.288 & -0.089 & 0.064 \\
\hline 42 & Teachers (low) & 0.414 & 0.017 & 0.144 & -0.106 \\
\hline 44 & Agricultural (medium) & -0.239 & -0.046 & -0.320 & -0.061 \\
\hline 46 & Technical (medium-low) & -0.109 & -0.245 & -0.068 & 0.124 \\
\hline 48 & Transport (medium) & -0.202 & -0.088 & -0.111 & -0.075 \\
\hline 49 & $\begin{array}{l}\text { (Para) medical } \\
\quad \text { (medium-low) }\end{array}$ & 0.149 & -0.054 & 0.014 & 0.101 \\
\hline 51 & $\begin{array}{l}\text { Administrative, } \\
\text { commercial, economic } \\
\text { (medium-low) }\end{array}$ & 0.007 & -0.021 & -0.020 & 0.102 \\
\hline 53 & Security (medium-low) & -0.037 & 0.016 & 0.082 & 0.020 \\
\hline 55 & Linguistic, cultural (low) & -0.011 & -0.118 & 0.047 & -0.008 \\
\hline 56 & $\begin{array}{l}\text { Societal, governmental } \\
\text { (medium) }\end{array}$ & 0.314 & 0.149 & 0.007 & 0.053 \\
\hline 57 & Care taking (medium) & -0.109 & -0.133 & -0.059 & 0.099 \\
\hline 62 & Teachers (medium) & 0.032 & 0.077 & 0.137 & 0.110 \\
\hline 64 & Agricultural (high) & -0.232 & 0.030 & -0.006 & -0.056 \\
\hline 65 & Scientific (medium) & -0.228 & -0.072 & 0.047 & -0.239 \\
\hline 66 & Technical (medium-high) & 0.030 & 0.087 & 0.021 & 0.016 \\
\hline 68 & Transport (high) & -0.075 & 0.092 & -0.098 & -0.125 \\
\hline 69 & $\begin{array}{l}\text { (Para) medical } \\
\text { (medium-high) }\end{array}$ & 0.215 & -0.007 & 0.042 & 0.031 \\
\hline 71 & $\begin{array}{l}\text { Administrative, } \\
\text { commercial, economic } \\
\text { (medium-high) }\end{array}$ & 0.092 & 0.135 & 0.028 & 0.111 \\
\hline 73 & Security (medium-high) & -0.068 & 0.088 & 0.086 & -0.088 \\
\hline 75 & Linguistic, cultural (high) & -0.138 & -0.025 & 0.102 & 0.018 \\
\hline 76 & $\begin{array}{l}\text { Societal, governmental } \\
\text { (medium-high) }\end{array}$ & 0.296 & 0.167 & 0.029 & 0.148 \\
\hline 78 & Managers (medium) & -0.194 & 0.066 & -0.023 & 0.051 \\
\hline 85 & Scientific (high) & -0.205 & 0.128 & 0.079 & -0.233 \\
\hline 86 & Technical (high) & -0.130 & 0.129 & 0.062 & 0.048 \\
\hline 89 & (Para) medical (high) & 0.044 & 0.095 & 0.025 & 0.085 \\
\hline 91 & $\begin{array}{l}\text { Administrative, } \\
\text { commercial, economic } \\
\text { (high) }\end{array}$ & 0.341 & 0.263 & 0.103 & 0.063 \\
\hline 93 & Security (high) & 0.187 & 0.289 & 0.126 & 0.074 \\
\hline 96 & Societal, governmental (high) & 0.304 & 0.256 & 0.026 & -0.090 \\
\hline 98 & Managers (high) & 0.013 & 0.116 & 0.037 & 0.066 \\
\hline
\end{tabular}




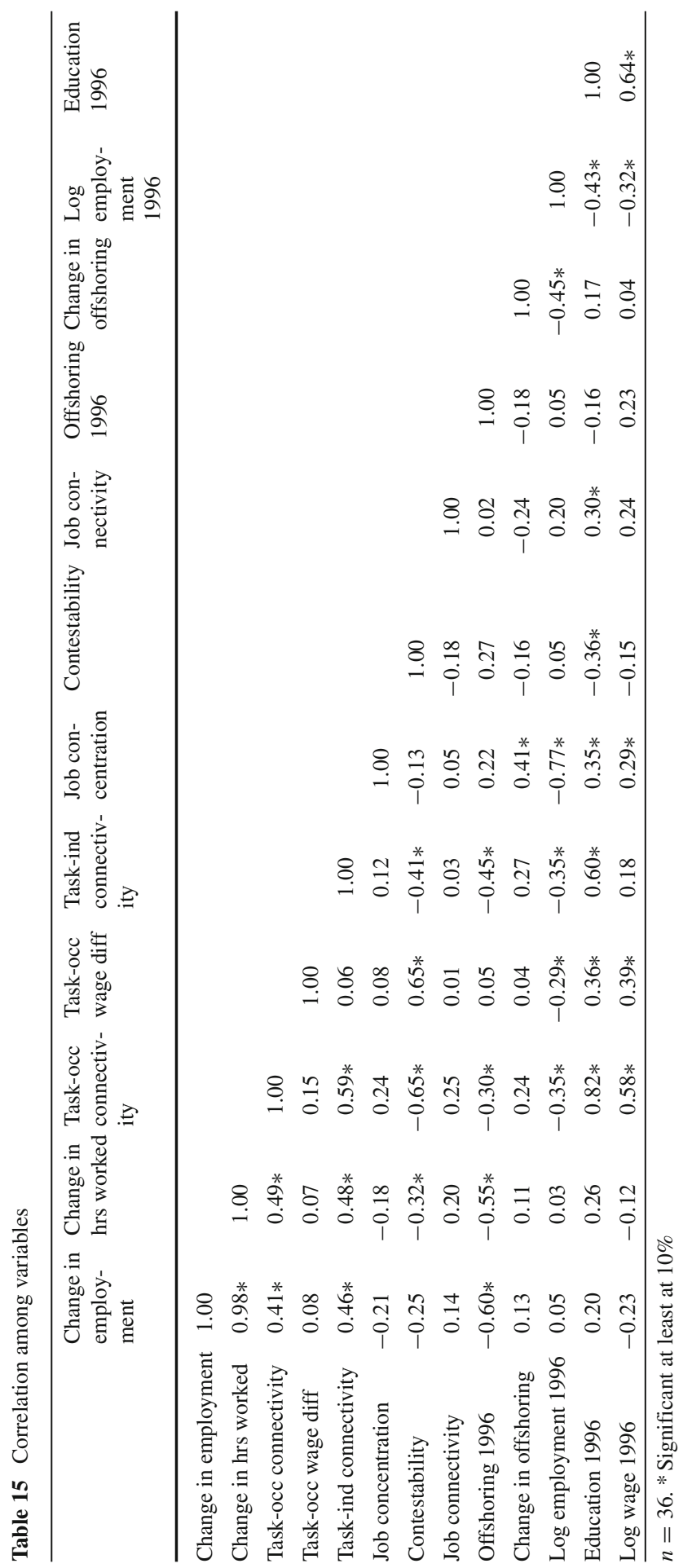




\section{Data Sources}

We have used a number of data sources to compile the dataset with which we have carried out the empirical analysis.

\section{British Skill Surveys (BSS)}

BSS is a data set that comprises particular information about the job-content of individuals: what tasks are exercised in a particular job and the importance of these tasks? The data set includes detailed information regarding the firm that the interviewee works (if employee), qualifications, education and other skills of the interviewee as well as personal data such as age, experience and gender of the interviewee.

BSS is conducted in three waves: 1997, 2001 and 2006. There are 2,467 observations in 1997; 4,470 observations in 2001 and 7,787 observations in 2006 wave, respectively. The questions for the importance of 36 tasks that we have employed in this study are asked in all years and measured exactly the same way in all three waves. There were some other questions measuring tasks importance in 2006 which were not asked in the earlier waves. We included only the tasks that are considered in all three waves. A typical question on tasks starts with a general explanation "You will be asked about different activities which may or may not be part of your job. At this stage, we are only interested in finding out what types of activities your job involves and how important of these are" followed by the question "In your job how important is ...". The answer categories range from (1) "essential" to (5) "not at all important". We adjusted this scale so that the scale increases with the importance of a task: (5) "task is essentially important" and (1) "task is not important at all".

The information on 36 tasks and other relevant variables are linked to EBB by using two-digit occupation codes. For each round of BSS, we came up with a correspondence table linking UK occupation classification [Standard Occupation Classification (SOC 1990)] codes to Dutch occupation classification [Standaard Beroepenclassificatie (SBC 1992)]. The crosswalk is first done at the two-digit level. For the occupation groups that we are not certain about the quality of the matching, we used three-digit codes. After reviewing the crosswalk, if we are still not satisfied, we used four-digit occupation codes. This procedure resulted in a correspondence table that matches 161 two, three and four-digit SOC codes to 36 SBC two-digit codes. We omitted all the codes that refer to general occupation classes such as 20, 40, 60 etc. This is first because, these classes do not have exact occupation definitions and more importantly the number of individuals registered to these occupation classes vary in great extent from year to year. For instance, occupation class 80 varies between 98 and 370 individuals, changing from year to year without a pattern. This applies for the other general groups as well. Some smaller categories that have less than $0.1 \%$ of total employment are also not considered. The omitted 9 occupation classes in total correspond to less than $1 \%$ of total employment. Once these classes are omitted we end up with 38 two-digit occupations. The three waves of BSS are aggregated for this 38 Dutch occupation classes. The correspondence table is available upon request. 


\section{Enquête Beroepsbevolking (EBB)}

We use the Dutch Labour Force survey from 1996 to 2005 for employment figures per occupation (2-digit, 1992 Dutch occupation classification, 47 occupation classes) and industry (2-digit, 1993 Dutch industry classification, 70 industry classes). EBB also comprises data on personal characteristics such as age, education, qualifications, gender, ethnic background and some other information regarding the content of the job. Unfortunately, EBB doesn't include wage data. We gathered wage data from the SSB at the occupation level from 1999 to 2005 and merge it to EBB. Wage data for earlier years are gathered from the Dutch Socio-economic Panel (SEP). For years 1999 and 2000 the wage data is present in both SSB and SEP. We used these two years to interpolate wages from 1996 to 1998. The number of observations in each EBB round ranges between 80,541 to 99,137 with an average of 89,746 .

\section{Input-Output Tables}

Input-output tables from 1996 to 2005 at CPB are used to compute the import component of inputs for each industry. We used both the total and import input-output tables for the Netherlands. The input-output tables comprise information on sales and purchases of each industry from and to other industries with additional information on other variables such as exports, final demand, total salary payments and social security contributions etc. giving a full account of the Dutch economy.

The industry classification of the I-O tables does not exactly follow the standard industry classifications. The I-O tables present detailed information for some two-digit industries. For instance, Chemical Industry is a standard two-digit class in Standaard Bedrijfsindeling 1993, but to provide better information this class is divided into five sub-categories in I-O tables. The tables are available for 112 industry classes and subclasses (112 by 112 matrix for each year). To match with the standard classification we constructed a correspondence table matching each 112 industry code to a two-digit Standaard Bedrijfsindeling 1993. This resulted in 70 two-digit industry classes. For each class we calculated offshoring and narrow offshoring indicators as explained in the main text. The correspondence table is available upon request.

\section{Dataset}

For the purpose of this project, the EBB data 1996-2005 is stacked in one large data set that comprises all relevant information from EBB for 10 years (the master data). This resulted in a data set of over a million observations. Then we add the necessary information from other data sets in 3 steps.

First, we append wage information. By using data from SSB and SEP as described above we came up with a data set of wages that comprise wage information for every two-digit occupation code from 1996-2005. This data is matched to the master data so that each two-digit occupation code has a corresponding wage for each year. 
Second, we add information from the BSS. We aggregated the data on tasks from BSS for Dutch two-digit occupations as explained above and than append this information to EBB master data such that each two-digit occupation code has a corresponding task measure for each year. Since there are only three waves of BSS, years 1996-1997 corresponds to BSS 1997 task values; 1998-2001 corresponds to BSS 2001 task values; and 2002-2005 corresponds to BSS 2006 task values.

Third, we append the offshoring measures that we calculated from the I-O tables. The 112 industry groups in the I-O tables were matched to 70 two-digit industry classes in the EBB as explained above. In the resulting data set each two-digit industry code has a corresponding offshoring coefficient.

The resulting master data set comprise information on age, education, gender, ethnicity, wages, tasks, other relevant information regarding the occupation and offshoring indicators. The data set has information for 10 years, 36 two-digit occupation classes and 70 two-digit industries. This data set can be aggregated in many ways, such as year-occupation, year-industry and even year-occupation-industry cells, depending on the analysis to be conducted.

Open Access This article is distributed under the terms of the Creative Commons Attribution Noncommercial License which permits any noncommercial use, distribution, and reproduction in any medium, provided the original author(s) and source are credited.

\section{References}

Acemoglu, D., \& Autor, D. H. (2011). Skills, tasks and technologies: Implications for employment and earnings. In: O. Ashenfelter, \& D. Card (Eds.), Handbook of labor economics (Vol. 4b, pp. 1043-1171)

Antràs, P., Garicano, L., \& Rossi-Hansberg, E. (2006). Offshoring in a knowledge economy. Quarterly Journal of Economics, 121(1), 31-77.

Autor, D. H., Levy, F., \& Murnane, R. J. (2003). The skill content of recent technological change: An empirical exploration. Quarterly Journal of Economics, 118(4), 1279-1333.

Autor, D. H., Katz, L. F., \& Kearney, M. S. (2006). The polarization of the U.S. labor market. American Economic Review, 96(2), 189-194.

Baldwin, R. (2010). Integration of the North American economy and new-paradigm globalisation. CEPR Discussion Paper No. 7523.

Baldwin, R., \& Robert-Nicoud, F. (2010). Trade in goods and trade in tasks: An integrating framework. NBER Working Paper No. 15882.

Baumgardner, J. R. (1988). The division of labor, local markets, and worker organization. Journal of Political Economy, 96(3), 509-527.

Becker, G. S., \& Murphy, K. M. (1992). The division of labor, coordination costs, and knowledge. Quarterly Journal of Economics, 107(4), 1137-1160.

Blinder, A. S. (2006). Offshoring: The next industrial revolution. Foreign Affairs, 85(2), 113-128.

Bloom, N., Garicano, L., Sadun, R., \& Van Reenen, J. (2009). The distinct effects of information technology and communication technology on firm organization. NBER Working Paper No. 14975.

Bolton, P., \& Dewatripoint, M. (1994). The firm as a communication network. Quarterly Journal of Economics, 109(3), 809-839.

Borghans, L., \& Ter Weel, B. (2004). What happens when agent $T$ gets a computer? The labor market impact of cost efficient computer adoption. Journal of Economic Behavior \& Organization, 54(2), 137-151.

Borghans, L., \& Ter Weel, B. (2006). The division of labour, worker organisation and technological change. Economic Journal, 116(509), F45-F72.

Borghans, L., Weel, B., \& Weinberg, B. A. (2006). People people: Social capital and the labor-market outcomes of underrepresented groups. NBER Working Paper No. 11985. 
Borghans, L., Ter Weel, B., \& Weinberg, B. A. (2008). Interpersonal styles and labor market outcomes. Journal of Human Resources, 43(4), 815-858.

Brakman, S., Garretsen, H., \& van Marrewijk, C. (2009). The New Introduction to Geographical Economics. Cambridge: Cambridge University Press.

Bresnahan, T. F. (1999). Computerisation and wage dispersion: An analytical reinterpretation. Economic Journal, 109(456), F390-F415.

Bresnahan, T. F., Brynjolfsson, E., \& Hitt, L. (2002). Information technology, workplace organization and the demand for skilled labor: Firm-level evidence. Quarterly Journal of Economics, 117(1), 339-376.

Bresnahan, T. F., \& Greenstein, S.(1996). Technical progress and co-invention in computing and in the uses of computers, Brookings Papers on Economic Activity: Microeconomics (pp. 1-77).

Caroli, E., \& Van Reenen, J. (2001). Skill biased organizational change? Evidence from British and French establishments. Quarterly Journal of Economics, 116(4), 1448-1492.

CPB. (2008). Centraal Economisch Plan. The Hague: Centraal Planbureau.

Crino, R. (2010). Service offshoring and white-collar employment. Review of Economic Studies, 77(2), 595632.

Criscuolo, C., \& Garicano, L. (2010). Offshoring and wage inequality: Using occupational licensing as a shifter of offshoring costs. American Economic Review, 100(2), 439-443.

Ellison, G., \& Glaeser, E. L. (1997). Geographic concentration in US manufacturing industry: a dartboard approach. Journal of Political Economy, 105(5), 889-927.

Ellison, G., Glaeser, E. L., \& Kerr, W. R. (2010). What causes industry agglomeration? Evidence from coagglomeration patterns. American Economic Review, 100(3), 1195-1213.

Feenstra, R. C., \& Hanson, G. (1996). Globalization, outsourcing and wage inequality. American Economic Review, 86(2), 240-245.

Feenstra, R. C., \& Hanson, G. (1999). The impact of outsourcing and high-technology capital on wages: Estimates for the U.S., 1972-1990. Quarterly Journal of Economics, 114(3), 907-940.

Firpo, S., Fortin, N., \& Lemieux, T. (2009). Occupational tasks and changes in the wage structure. University of British Columbia, Working Paper.

Garicano, L., \& Rossi-Hansberg, E. (2006). Organization and inequality in a knowledge economy. Quarterly Journal of Economics, 121(4), 1383-1435.

Gaspar, J., \& Glaeser, E. (1998). Information technology and the future of cities. Journal of Urban Economics, 43(1), 136-156.

Goos, M., \& Manning, A. (2007). Lousy and lovely jobs: The rising polarization of work in Britain. Review of Economics and Statistics, 89(1), 118-133.

Goos, M., Manning, A., \& Salomons, A. (2009). Job polarization in Europe. American Economic Review, 99(2), 58-63.

Gorter, J., Tang, P., \& Toet, M. (2005). Verplaatsing vanuit Nederland, CPB Document No. 76.

Green, F., Felstead, A., Gallie, D., \& Zhou, Y. (2007). Skills at Work, 1986-2006, SKOPE, University of Oxford, http://www.skope.ox.ac.uk/publications/skills-work-1986-2006.

Green, F. (2009). Employee involvement, technology and job tasks, University of Kent, Department of Economics, Discussion Papers in Economics No. 09/03.

Grossman, G. M., \& Rossi-Hansberg, E. (2008). Trading tasks: A simple theory of offshoring. American Economic Review, 98(5), 1978-1997.

Jensen, B., \& Kletzer, L. G. (2005). Tradable services: Understanding the scope and impact of services offshoring, Institute for International Economics Working Paper No. 05-9.

Osterman, P. (1994). How common in workplace transformation and who adopts it?. Industrial and Labor Relations Review, 47(1), 173-188.

Radner, R. (1993). The organization of decentralized information processing. Econometrica, 61(5), 11091146.

Spieza, V.(2003). Geographic concentration and territorial disparity in OECD countries, http://www. oecd.org/dataoecd/43/1/15179757.doc accessed on 02/03/2010.

Spitz-Oener, A. (2006). Technical change, job tasks and rising educational demands: Looking outside the wage structure. Journal of Labor Economics, 24(2), 235-270.

Ter Weel, B., van der Horst, A., \& Gelauff, G. (2010). The Netherlands of 2040. The Hague: Centraal Planbureau.

Ter Weel, B. (2003). The structure of wages in the Netherlands, 1986-1998. Labour, 17(3), 361-382.

Ter Weel, B. (2006). IT diffusion and industry and labour-market dynamics. Economic Journal, 116(509), F1-F9. 
Varian, H. R. (2010). Computer mediated transactions. American Economic Review, 100(2), 1-10.

Venables, A. J. (2001). Geography and international inequalities: The impact of new technologies. Journal of Industry Competition and Trade, 1(2), 135-159. 